Revista de Ciencias Sociales - Número 66 (2015) - Páginas 13-61

La fragmentación del discurso práctico, o el plano medio...

\title{
LA FRAGMENTACIÓN DEL DISCURSO PRÁCTICO, O EL PLANO MEDIO EN EL QUE VIVE EL DERECHO
}

\author{
THE FRAGMENTATION OF THE PRACTICAL \\ DISCOURSE, OR THE MIDDLE PLANE \\ IN WHICH LAW IS LIVING
}

\author{
FRANCISCO CARPINTERO BENÍTEZ* \\ Universidad de Cádiz (España) \\ francisco.carpintero@uca.es
}

\section{Resumen}

El empirismo propio de la Edad Moderna, que se prolonga aun hoy, ha negado la cualidad personal del ser humano y la posibilidad de la ontología en el derecho, es decir, de la ciencia jurídica. Esta negación ha sido consecuencia de la negación previa de las 'sustancias', tal como vemos en los sistemas de Hobbes o Locke. En su lugar los empiristas han propuestos síntesis a priori o definiciones genéticas en las que los elementos avanzados en virtud del método tasan anticipadamente las posibilidades argumentativas. El Autor apunta a los nervios más importantes de estas definiciones genéticas y recaba el estudio de las realidades concretas. Indica que quien entienda que los argumentos que hay que dar a un funcionario que comete cohecho, a un ladrón vulgar o a una mujer que vende su cuerpo son argumentos necesariamente distintos, se situará en condiciones de entender mejor el trabajo jurídico.

* Doctor en Derecho, Catedrático de Filosofía del derecho. Artículo recibido el 28 de septiembre de 2014 y aceptado el 6 de abril de 2015.

Revista de Ciencias Sociales - Número 66 (2015) - Universidad de Valparáíso - ISSN 0716-7725-Valparaíso, Chile 


\title{
Palabras clave
}

\begin{abstract}
Método, constructivismo, constructo, ontología, persona, empirismo. Abstract

The empiricism inherent to the Modern Age, which lasts even nowadays, has denied the personal quality of the human being and the possibility of ontology in Law, that is, of the legal science. This denial has been a result of the previous denial of the 'substances', as we can see in Hobbes and Locke's systems. Instead, empiricists have proposed a priori synthesis or genetic definitions in which the elements advanced according to their method limit beforehand the argumentative possibilities. The Author points to the most important nerves of these genetic definitions and asks for the study of the concrete realities. He indicates that anyone who understands that the arguments which must be given to an officer who commits bribery, to a common thief or to a woman who sells her body are necessarily different arguments, will be placed in a position to understand better the legal work.
\end{abstract}

\section{Keywords}

Method, constructivism, construct, ontology, person, empiricism.

\section{Introducción}

El empirismo, al negar la pluralidad de las cosas y de las cualidades ha propuesto, para hacer justicia, diversos constructos intelectuales que se han sucedido desde el siglo XVII con Thomas Hobbes, hasta hoy con John Rawls, entre otros. Estos constructos consisten en definiciones genéticas, y lo procedente es preguntarse si una definición, montada sobre un rasgo de lo humano, puede hacer justicia a la pluralidad de la realidad.

Tenemos hoy teorías sobre la justicia, y parece que todas ellas fundamentan su pretensión de superioridad sobre las doctrinas jusnaturalistas actuales en la negación de la ontología y de la metafísica. Han de desconocer la noción que es en mayor grado metafísica, que es la de persona. Si no estamos de acuerdo con este planteamiento, parecería que es el momento de hacer algo así como un manifiesto personalista. Pero los problemas que plantea el tratamiento doctrinal

Facultad de Derecho y Ciencias Sociales - Universidad de Valparaíso - Chile 
de la índole personal de lo humano no se resuelve sin más afirmando o insistiendo en esta cualidad de los hombres; porque andan también en juego cuestiones epistemológicas que apuntan hacia la negación de la ontología para explicar el derecho, de modo que la negación de esta qualitas personalis dependería, prima facie, de estas otras cuestiones. Pues hay quienes entienden que en primer lugar es preciso establecer ante todo una teoría epistemológica y, solamente ya asentada esta teoría, proceder a tratar más sustantivamente estos temas.

Pero situémonos en la realidad: una persona que no esté en Babia diría que ante todo se adopta una actitud doctrinal que depende de una toma de posición personal y que solamente después cada cual afirma o niega la personalidad humana; por donde vemos que los temas epistemológicos constituyen un posterius de una decisión que ya ha sido tomada. Jellinek, explicaba a comienzos del siglo XX que existen dos actitudes ante los temas más básicos del derecho ${ }^{1}$. Ahora no trato de convertir este estudio en un tema confesional, pero es necesario tomar en serio esta observación de Jellinek porque es innegable que las actitudes últimas determinan pesadamente lo que podamos escribir sobre los fundamentos del derecho y de los derechos ${ }^{2}$. Como las pugnas se suelen entablar normalmente en temas periféricos del centro de la cuestión en debate, parece preferible aludir a esta periferia cuasi extramuros que no entrar en estos problemas al modo como el general Pavía entró en el Parlamento, montado en su caballo.

1. Georg Jellinek escribía que "Eine flüchtifer Blick in die Literatur lehrt, dass eine und dieselbe und daher aufhebende Ursache zurückgefürt wird. So ist dem Eine moderne Kultur eine christliche, also ein Produkt des christlichen-religiöse Geistes, während der andere in die Ueberwindung der religiösen durch die naturwissenchafliche nitchs als Ergebniss ungeheurer sociales Menschenwirkungen”. Das Recht des modernen Staates, Erster Band, Allgemeine Staatslehre, Berlin, 1900, p. 85. Años antes, Rudolph von Jhering había reconocido que la revuelta de los moderni fue ante todo contra la Iglesia. Vid. Der Zweck im Recht, Leipzig, $4^{\text {a }}$ ed., 1904, vol. II, p. 135.

2. ¿Es correcto aludir a factores religiosos en el momento de mostrar el desarrollo de una actitud filosófica? Hobbes nos animaba a que fuéramos realistas, porque ¿acaso no buscamos la compañía de hombres de armas cuando hemos de hacer un viaje? Seamos realistas también en este punto.

Revista de Ciencias Sociales - Número 66 (2015) - Universidad de Valparáíso - ISSN 0716-7725-Valparaíso, Chile 
He aludido a las actitudes últimas, y parece que mencionarlas implica romper las cartas de la baraja con que todos jugamos cotidianamente el juego universitario. Desde luego, éste es un tema delicado porque la mención o la denuncia de las actitudes más personales conduce a una calle sin salida, ya que cualquiera puede decir: ¿Por qué me reprochas a mí lo que hacemos todos? Planteado así el problema, parece que únicamente cabe un silencio respetuoso ante las actitudes diversas. Si viviera en el siglo XVII y asistiera a una discusión entre los partidarios de Galileo y de Descartes, haría bien en callarme, porque ambos contendientes disponían de buenos argumentos propiamente científicos, e hizo falta la obra de Newton para mostrar la relativa cientificidad de ambas actitudes. Pero han pasado los tiempos de Galileo, Descartes o Newton y con ellos se han evaporado diversas evidencias científicas de alcance pretendidamente universal que les eran imprescindibles a cada investigador, fuera cual fuera el bando al que se incorporara. Es decir, lo que pudiéramos llamar las razones-pretexto han desaparecido, y como ahora el investigador ya no puede escudarse tras ellas, ha de poner sobre la mesa todas sus cartas, ya algo desvalorizadas, y explicar lo que él vivencia. Pues antes y por debajo de toda teoría está operativa lo que podríamos llamar una protheoria, que equivale al director de la orquesta con su batuta, y esta dependencia determina la existencia, algo deprimente, de lo que Gonseth llamaba philosophies nécessitaires ${ }^{3}$. No parece que sea posible realizar una teoría general del carácter dependiente de estas filosofías, examinando los vínculos entre los factores condicionantes y las opiniones condicionadas. Pero siempre será lícito mostrar estas dependencias y, procediendo aún más allá, cuestionar si es posible mantener lo condicionado una vez

3. Gonseth escribía: "Si le quadre de ce travail le permittait encore, c'est n'est pas l'histoire de la géometrie sous son aspect théorique que nous songerois à refaire, mais celles des doctrines préalables (les plus souvent implicites) selon lasquelles la vérité geométrique s'accord avec l'aspect phisique et avec l'image que les sens procurent de celle-ci. Cette histoire est à faire". La géometrie et les problèmes de l'espace, Dunond Éditeur (Paris)—Éditions du Griffon (Neuchâtel), Neuchâtel, 1955, vol. VI, p. 529. El lector puede comprobar que la reconstrucción de cualquier doctrina epistemológica pasa por denunciar la confusión de los conceptos con la imagen física que los subyacen; estas imágenes constituyen usualmente el armazón más destacado de estos prosilogismos omnipresentes.

Facultad de Derecho y Ciencias Sociales - Universidad de Valparaíso - Chile 
que ha perdido su valor la visión del mundo que sustentaba la actitud aparentemente filosófica.

\section{Los positivistas, lastrados por sus bases empiristas}

Desde Hobbes a hoy, unos se han refugiado en el empirismo, y otros han pretendido mostrar algunas bases de los principios de la justicia que sean más sólidas que las que ofrecen el lenguaje o la historia. Los acogidos a la epistemología empirista han compuesto el grupo de los positivistas; como el empirismo es cosa distinta del positivismo, ruego al lector que perdone esta imprecisión inicial, pero la uso porque es útil para aclarar el tema en un primer momento. Porque ha sucedido que los positivistas han profesado, de hecho, epistemologías empiristas en la filosofía práctica que les han permitido mantener su escepticismo ético al servicio de su asepsia científica (valorativa) en el plano teórico. Ellos entendían que la imposibilidad de conocer teóricamente el 'Ser' objetivo, conllevaba la negación del conocimiento del 'Deber-ser'.

¿Por qué estas extrañas discusiones sobre la derivación del Deberser desde el Ser? Los empiristas trataban de oponerse a la mentalidad, expresada especialmente por los escolásticos tardíos que, desde el siglo XVII a hoy, han mantenido que el Deber-ser se fundamentaba en el $\mathrm{Ser}^{4}$. Ha sido extraño que la metafísica y la ontología hayan ido unidas en esta negación común, que no encuentra explicación desde los moldes filosóficos usuales. La negación en gros de la metafísica y de la ontología sólo se puede entender desde las exigencias del final del proceso práctico: era preciso negar la existencia de una moral objetiva y para conseguir esto era necesario negar cualquier entidad que pudiera tener carácter 'sustantivo'; las diatribas de Hobbes, y especialmente de Locke, contra las 'sustancias' muestran hasta qué punto nuestra reflexión filosófica se ha visto urgida a negar la 'realidad', identificada en un primer momento con las sustancias. Frente a la metafísica y la ontología, para negar la eticidad de lo que es o existe, las teorías empiristas ofrecieron - y ofrecen también hoy - un fundamento que de facto es socialmente aceptado

4. Vid. Kelsen, Die Grundlage der Naturrechtslehre, en "Österreiche Zeitschrif für öffentliche Recht”, XIII, pp. 1-37.

Revista de Ciencias Sociales - Número 66 (2015) - Universidad de Valparaíso - ISSN 0716-7725-Valparaíso, Chile 
en algunos sectores de los universitarios. Al hablar de la aceptación social del empirismo nadie afirma que tales teorías exhiban títulos suficientes para ser aceptables, sino que los positivistas han recurrido a un fundamento que es afirmado habitualmente por los universitarios de izquierdas. Bajo estos condicionantes, Kelsen fue positivista y se opuso tenazmente a los empiristas escandinavos; pero su actitud más básica epistemológica era también empirista. Para superar el empirismo inicial y entrar por un camino más positivista que le permitiera apartarse de los de Uppsala, él hubo de buscar la extraña figura del Deber-ser como una constante del psiquismo humano; para ello se remitió a algunas de las enseñanzas de los neokantianos de aquel momento, que aún hablaban de los principios a priori del Entendimiento, aunque (parece) en un sentido algo apartado de Kant. Kelsen montó — desde su base epistemológica inicialmente empirista - la estructura de las doctrinas positivistas dominantes en el siglo $\mathrm{XX}^{5}$.

Estas explicaciones pretenden únicamente aludir a las génesis de unas construcciones intelectuales que se apartan del sentido común gracias al cual vivimos pacíficamente la cotidianidad ${ }^{6}$. Pues lo cotidiano está dominado y regido por vivencias inmediatas que no requieren de teorías reflexionadas y nadie razona los derechos que nos permiten vivir

5. Antes, algunos autores del siglo anterior, como Austin o Holland, habían creado la Analytical School, que producía la ciencia nueva de la Jurisprudence, que había de mostrar las estructuras lógicas necesarias del derecho positivo. En la Alemania decimonónica se estaba desarrollando la doctrina de los Allgemeine Grundbegriffe. Pero Kelsen fue sin duda alguna, el mejor notario de las vivencias de buena parte del siglo XX sobre el derecho.

6. Es difícil determinar los límites de las abstracciones en el momento de explicar la ciencia jurídica. Nicolaeus Falck, desde un ángulo muy estrictamente jurídico-civilista, explicaba que los tres requisitos imprescindibles para proponer una verdadera ciencia del derecho eran la plenitud, la Gründlichkeit y el orden. La ciencia del derecho no puede, por tanto ser científica porque ella depende de la experiencia. Vid. Juristische Encyclopädie, Kiel, 1821, § 19. Pero a tenor de estas exigencias, habría que concluir que el Corpus Juris no expone ciencia del derecho. También es verdad que Savigny explicaba que hoy (1840) los juristas se enfrentan a una tarea más difícil que la de los juristas romanos. Vid. System der heutigen römischen Rechts, Berlin, 1840, Band I, Prólogo, p. XXX.

Facultad de Derecho y Ciencias Sociales - Universidad de Valparaíso - Chile 
diariamente. ¿Por qué, entonces, tanta literatura? Este origen ha estado claro históricamente: la mayor parte de los constructos político-jurídicos que han llegado a las imprentas desde el siglo XVII a hoy, han sido desarrollos argumentativos que han tratado de introducir fundamentaciones para los derechos humanos. Han consistido en desarrollos simplemente intelectuales porque han proseguido el sueño de Rousseau: encontrar una forma de gobierno que, por el simple hecho de funcionar como ella es, vuelva inútiles las pasiones de los hombres, esto es, conseguir que la bondad institucionalizada vuelva superfluas las virtudes personales. Realmente, ¿es posible diseñar los trazos fundamentales de una sociedad en la que la prepotencia o los robos queden excluidos teóricamente en virtud de la fuerza de esos mismos rasgos? Habría que abstraer mucho, en realidad demasiado, y parece que finalmente llegaríamos a un diseño de Perogrullo. Por esto, es necesario cuestionar la separación entre derecho y moral que ellos exigen porque tal separación está lejos de hacernos comprender la vida concreta de todos los días.

El escepticismo moral llevado a las explicaciones sobre el derecho gravitó pesadamente sobre la cultura triunfante en la II Guerra Mundial. Fueron varias las instancias que levantaron un dedo acusador contra la separación entre la moral y el derecho: los juristas alemanes habían sido educados, desde comienzos del siglo XIX, en la obediencia estricta a los mandatos del legislador ${ }^{7}$, y para hacer posible esta obediencia, diversas doctrinas, triunfadoras en la práctica jurídica, habían mantenido

7. P. J. A. Feuerbach, haciéndose eco de la communis opinio vigente en los territorios alemanes a comienzos del siglo XIX, ya indicaba que el hombre como hombre puede pensar lo que quiera, pero como ciudadano está sometido a las leyes positivas. Vid. Über Philosophie und Empirie in ihrem Verhältnis zur positiven Rechtswissenschaft, Frankfurt/Main, 1869 (Landshut, 1804), p. 72. Añadía que el juez que no obedece a las leyes es un falsario y un rebelde. Vid. op. cit., p. 73.

Sucedía entonces lo que explica hoy Hattenhauer, que los jueces fueron vistos como máquinas de subsumir. Vid. Los fundamentos históricos-ideológicos del derecho alemán. Entre la jerarquía y la democracia, trad. M. Izquierdo, Edersa, Madrid, $2^{a}$ ed., p. 91. Este mismo autor, desde una perspectiva más amplia, nos indica que la judicatura no fue entendida como un poder independiente. La doctrina alemana entendió que sólo existían los otros dos poderes. Vid. Los fundamentos.., cit., p. 151.

Revista de Ciencias Sociales - Número 66 (2015) - Universidad de Valparáíso - ISSN 0716-7725-Valparaíso, Chile 
la inexistencia de una moral objetiva ${ }^{8}$. Extrañamente, por motivos no fácilmente comprensibles, los últimos decenios del siglo XIX alemán se desentendieron del problema de la moral y centraron sus tiros contra cualquier forma de las doctrinas sobre el derecho natural. Así procedió Carl Bergbohm en sus dos obras más conocidas ${ }^{9}$. Posiblemente haya que buscar la razón de esta sustitución en el hecho de que, efectivamente, los ataques a la moral habían alcanzado ya el éxito de público ${ }^{10}$.

8. Para conocer algunos de estos ataques a la moral, recomiendo la lectura de la parte histórica de mi estudio Una introducción a la ciencia jurídica, Civitas, Madrid, 1988. Estudio disponible en la web franciscocarpintero.com. El lector puede encontrar más datos sobre este tema en otro de mis estudios, Los inicios del positivismo jurídico en Centroeuropa, Actas, Madrid, 1993.

9. Este alemán, en un tono desgarrado y excesivamente apasionado, indicaba: "Sie fragen uns, ob wir es denn nicht 'fühlten', das Versprechen gehalten, fremdes Gut respektieren, Übelthäter bestraft werden müssten und dgl. Diese einerseits abstrakte falsch generalisierende Weise verschliesst jedoch den Weg zur Einsicht. Niemand, schlechthin niemand 'fühlt' dergleichen”. Cfr. Jurisprudenz und Rechtsphilosophie. Leipzig, 1892, p. 467. Debían gustarle las frases que le salían 'logradas', porque en su Das Naturrecht der Gegenwart, Leipzig, 1892, en la p. 467, repite exactamente las mismas líneas.

Sin embargo, en esta misma obra, página 415, explica que "Mord hingegen bleibt immer Mord und ewig rechtswidrig und strafbar ... der Vertrag sei ein ewiges Rechtsinstitut, das überall und immer unter gleichen Hauptnormen stellt". ¿Entonces? Él se lanzó a sí mismo este problema, y no lo contestó.

10. Era tal la desvinculación entre el plano ético y jurídico, que Jhering mantenía, entre el aplauso popular, que el secreto para trabajar en el arte jurídico estaba en saber interesar a los demás en el propio egoísmo: "Die Egoismus in Dienste fremder Zwecke”. Der Zweck im Recht, cit., p. 24. Fue lógico que mantuviera que el derecho, en sustancia, es puro egoísmo. Sobre esto último, vid. op. cit., p. 191.

Como suele ser habitual en él, Jhering introduce tardíamente otras consideraciones en las que no matiza lo anterior expuesto, sino que lo contradice. Vid. op. cit., pp. 340-341, en donde habla de medir la rectitud del derecho desde sus fines, o bien cuando indica que el derecho es un orden normativo, por lo que no vale cualquier contenido, p. 342. En la página 345 afirma como función del derecho asegurar las Lebensbedingungen de la sociedad. En el segundo volumen de esta obra abunda en este tipo de consideraciones. 313, vol. II. Al final de esta obra adopta una actitud descaradamente jusnaturalista y mantiene que el derecho no está sometido a un perpetuo cambio arbitrario: hay acuerdo en las instituciones jurídicas fundamentales,

Facultad de Derecho y Ciencias Sociales - Universidad de Valparaíso - Chile 
Como después de 1945 los positivistas tenían mala conciencia, algunos de ellos rectificaron algo y sin renunciar a su empirismo ético inicial, se lanzaron a exponer doctrinas sobre la justicia, que eran teorías que, como es comprensible, carecían de bases que superaran los datos ofrecidos por el lenguaje o por la sociología. Rudolf Stammler ya había emprendido unos años antes esta empresa ${ }^{11}$, pero su neokantismo ya estaba fuera de lugar históricamente. Además, aparecieron entonces corrientes hermenéuticas y neojusnaturalistas. Las doctrinas hermenéuticas han sido expuestas en España por el admirador más destacado de Arthur Kaufmann, otra vez Ollero ${ }^{12}$; los nuevos jusnaturalismos fueron historiados por Rodríguez Molinero ${ }^{13}$, y parece preferible ahora dejar de lado estas vertientes de la Filosofía del Derecho. Interesan más en este momento los filósofos del derecho que, desde bases empiristas (aunque se han llamado a sí mismos positivistas) han propuesto variantes del positivismo jurídico y, más tardíamente, algunas teorías sobre la justicia. Un primer grupo de estos filósofos sería el compuesto por los positivistas más rancios, tales como Bergbohm,

que son como el Jus Gentium romano, que expresaba el universale Element des Rechts. El acuerdo no es arbitrario o casual, sino debido a la objetive Vernunft der Dinge, o a la Natur der Sache. Op. cit., vol. II, p. 313. Cito a Jhering porque es uno de los filósofos más representativos de toda Europa en aquel momento. Él era materialista porque se expresaba como tal, y es patente que era leído por personas razonablemente materialistas, que no creían en ninguna moral objetiva aunque procedían con cautela bajo la mirada del Káiser. Sobre su materialismo, si no explícito sí claro, vid. su artículo Die geschitliche-gesellschatlich Grundlagen der Ethik, en "Jahrbuch für Gesetzgebung, Verwaltung und Volkswirtschaft” (conocidos comúnmente como los Smoller's Jahrbücher) 6. Jahrgang, 1882, Erstes Heft.

11. Además de su obra más básica — la Filosofía del derecho, que gozó de varias traducciones y ediciones - es instructiva la lectura de un estudio más breve, las Rechts-und Staatstheorien der Neuzeit. Leitsätze zu Vorlesungen, Verlag von Veit and Co., Leipzig, 1917. Aquí examina las dieciocho corrientes del pensamiento jurídicopolítico más extendidas en su tiempo, y las critica una a una.

12. Vid. Derechos humanos y metodología jurídica, CEC, 1989.

13. Vid. Derecho natural e historia en el pensamiento europeo contemporáneo, Editorial Revista de Derecho Privado, Madrid, 1973.

Revista de Ciencias Sociales - Número 66 (2015) - Universidad de Valparáíso - ISSN 0716-7725-Valparaíso, Chile 
Kelsen, Bobbio o Hart; hubo diferencias entre ellos, pero todos coincidieron en mantener la separación entre la moral y el derecho. La segunda corriente, que propone sistemas intelectuales para hacer justicia, ha estado representada en el Continente ante todo por Apel y Habermas, y en tierras americanas, especialmente por John Rawls. Es patente que muchos de los nuevos teóricos de la razón práctica quedan sin mencionar en este momento; pero es preferible, en esta exposición tan sucinta, dejar de lado a los de la Escuela de Erlangen y a tantos otros anglosajones que hablaron tanto de la razón práctica que finalmente consiguieron que el estudio de esta vertiente de la razón llegara a ser una cosa bastante poco práctica.

Sin metafísica y sin ontología no queda otra salida que diseñar intelectualmente algún constructo que no tenga en cuenta —es decir, que no deba tener en cuenta-fundamentalmente a las cosas ni a las personas. Las personas han de quedar diluidas en alguna faceta suya que será prolongada según las reglas de la lógica al servicio de su mayor mejor sociabilidad; obviamente es una forma de proceder que sólo puede presentar versiones light de la personalidad. ¿Realmente, estas teorías se emancipan de las determinaciones humanas con las que nos relacionamos continuamente? Como Hegel afirmó positivamente - en líneas generales - lo ofrecido por la historia, algunos investigadores tratan de llenar este vacío ontológico manteniendo que Rawls se aproxima a Hegel porque ambos tienen en común su consideración positiva del Lebenswelt. Pero esta observación no parece admisible: Rawls desdeña expresamente el Lebenswelt que él conoce ${ }^{14}$, y Hegel trató más bien de mostrar el desarrollo del Geist en la historia sacralizando de alguna forma sus momentos.

Los positivistas añejos y los propugnadores de teorías nuevas sobre la justicia, para suplir la carencia de una base que les permita afirmar que somos 'personas' (la noción máximamente metafísica) o que el

14. Este autor escribe que "Se afirman o profesan muchas doctrinas comprensivas razonables, y no todas pueden ser verdaderas (en realidad, ninguna de ellas puede ser verdadera)". Liberalismo político, trad. S. R. Madero, FCE, México, 1996, Conferencia I, "Ideas Fundamentales", p. 76. Es una declaración abierta de guerra contra la mentalidad que representa Hegel.

Facultad de Derecho y Ciencias Sociales - Universidad de Valparaíso - Chile 
profesor tiene el deber objetivo de explicar con claridad (un dato que proviene desde la consideración simplemente ontológica de lo que es la docencia), han propuestos teorías conceptuales a las que podemos llamar constructos si ése es nuestro gusto. Adelanto que el que usa constructos para acceder a su objeto de estudio o, lo que es más normal, para crear este objeto, cae bajo el dominio de lo que Ferdinand Gonseth llamaba philosophies nécessitaires ${ }^{15}$, y ocultan que toda tentativa de expresarse en términos precisos y definidos —obtenidos desde aquella filosofía anterior- prejuzga ya la solución. Pues cuando es imposible el conocimiento 'directo' de un objeto que quiere sin embargo ser afirmado, los universitarios suelen idear cuerpos de conceptos que tratan de ser coherentes, y mantienen que esos conjuntos de teoremas componen el esquema necesariamente intermedio - y verdaderamente científico- que media entre el objeto estudiado y la racionalidad del hombre. Habermas y Apel son especialmente conscientes de la insuficiencia de sus bases empiristas para hablar siquiera de los derechos; con cierta honestidad explican que han de incurrir en una petición de principio $^{16}, \mathrm{y}$ mediante este asumir su contradicción inicial —un recurso retórico- convierten sus primeros datos afirmadamente fenoménicos en cuasi-noúmenos posteriores. Rawls más pragmático, no recurre a noúmenos que habitan en el lenguaje (¿puede hacer esto un norteamericano?), y en su segunda obra, "Liberalismo político", quiere corregir el determinismo psicológico sobre el que había montado la primera versión de su Teoría de la Justicia, y para esto recurre al tono enérgico propio de un predicador dominical animando a actuar solidaria y cooperativamente en el interior de una sociedad democrática.

Es lícito que nos preguntemos sobre el porqué de este juego de enredos. Sucede que hay investigadores que quieren afirmar la idea de la justicia, pero que tienen miedo a ser tachados de jusnaturalistas (¿Qué se puede entender hoy por jusnaturalista?). Esta actitud les lleva a ser políticamente correctos y, por tanto, a dirigir sus miradas directamente

\footnotetext{
15. Vid. Mon itinéraire philosophique, "Dialectica” XX (1966) pp. 419 y ss.

16. Vid., A. Cortina, Razón comunicativa y responsabilidad solidaria. Ética y política en K.O. Apel, Sígueme, Salamanca, 1985.
}

Revista de Ciencias Sociales - Número 66 (2015) - Universidad de Valparáíso - ISSN 0716-7725-Valparaíso, Chile 
hacia algún tipo de constructo, sea del tipo del de Habermas, o del de Rawls. Desde estos conjuntos axiomáticos deducen los derechos de los seres humanos, siempre siguiendo los resultados prácticos de la aplicación de alguna variante de la regla de la igualdad aritmética; pues la razón humana, cuando quiere prolongar los datos ya dados por la psicología o por la sociología, sólo dispone de las exigencias de la igualdad según esquemas binómicos.

Entendamos este tema en su anchura. La idea de la igualdad no se refiere, o no se agota, en afirmar la igualdad de derechos o la igualdad de las posibilidades de los ciudadanos ante las leyes. Ésta es la nota más básica del Estado de Derecho, y ahora el estudio no está limitado a este tipo de Estados, sino que alcanza a las teorías sobre la justicia, unas teorías que, entre otras cosas, exigen este tipo de Estado. La igualdad de los ciudadanos ante las leyes surgió históricamente desde la afirmación de cada ser humano como una persona: un tema de la Escuela de los Nominales de la Baja Edad Media que fue recogido por jusnaturalistas destacados del siglo XVII ${ }^{17}$. En cambio, el uso prácticamente omnipresente de las exigencias dialécticas sobre la igualdad desbordó los condicionantes teológicos de aquellos teólogos y adentró el discurso de los teóricos del derecho de las Edades Moderna y Contemporánea en el mos geometricus. Obviamente, la crítica expuesta ahora no se refiere a las exigencias que se derivan de la igual dignidad de los seres humanos, sino al empleo a fondo, en sede teórica, de una vaga idea de igualdad en la que no queda claro si tal igualdad es de tipo geométrico o aritmético. Tampoco queda esclarecido por qué, si tal igualdad es simplemente aritmética, ha de tener operatividad en las reflexiones sobre la ética social. Pues una cosa es una exigencia concreta, y otra realidad distinta es el desgranamiento de esa cosa en cada reflexión que haga el teórico. Este uso indiscriminado de la exigencia de igualdad no vuelve al discurso ni más riguroso ni más científico: denota ante todo pobreza argumentativa.

Comprobamos este hecho si examinamos las teorías de la justicia desde el siglo XVII a hoy: ésta es una limitación lacerante — buscada

17. Vid. mi estudio La ley natural. Historia de un concepto controvertido, Encuentro, Madrid, 2008, pp. 249 y ss.

Facultad de Derecho y Ciencias Sociales - Universidad de Valparaíso - Chile 
expresamente- de la racionalidad que pretende ser autónoma en cuanto racional, esto es, en cuanto instancia autónoma que no quiere pedir nada en préstamo a otro plano de la realidad que no aparezca ante todo como constitutivo de la racionalidad del hombre en cuanto hombre. En realidad, esta racionalidad igualitaria quiere construir ella misma las bases de la justicia, y por esto hablamos de actitudes constructivistas en la ética y de los constructos elaborados por los que siguen esta actitud básica. Bekker — un importante pandectista de finales del siglo XIX - publicó a finales del siglo XIX una obra cuyo solo título muestra su beligerancia: "El derecho como obra humana y sus fundamentos": Das Recht als Menschenwerk und ihre Grundlagen ${ }^{18}$. Nadie pone en duda que la limitación de la velocidad a $120 \mathrm{kms} / \mathrm{h}$. es una obra humana; pero tampoco nadie puede dudar de que el deber del conductor de llevar su auto prudentemente se debe a algo más que a un reglamento de tráfico. El problema confesional está siempre latiendo en la base de estas teorías. La advertencia de Georg Jellinek era pertinente.

\section{La uniformidad y homogeneidad de la materia a explicar}

Los positivistas al antiguo uso explican que los derechos existen, pero sin ninguna base más allá del lenguaje, de la historia, o de los sentimientos extendidos; si plantean así este problema, nadie les hace injuria si no los trata. Si nos vamos al campo de los constructos más modernos, echamos de menos a las personas humanas en Habermas y en Rawls; sus obras exhiben seres sin rostros ni funciones o necesidades propias, pero que están sometidos a las reglas a priori del lenguaje ideal, o que son capaces de calcular las consecuencias de sus decisiones y de desear las situaciones que sean lo menos malas posibles para todos, también para la persona que razona individualmente. Ellos se remiten a personas concretas, al menos como punto de atribución de los derechos — ¿de qué otro modo podría ser? - y lo propio de la personalidad es su incomunicabilidad, desde la que surge, entre otras notas, la de

18. Immanuel Bekker, Das Recht als Menchenwerk und seine Grundlagen, Carl's Winter, Universitätsbuchhandlung, Heidelberg, 1912.

Revista de Ciencias Sociales - Número 66 (2015) - Universidad de Valparaíso - ISSN 0716-7725-Valparaíso, Chile 
irrepetibilidad. Pero ya indiqué que estos constructos sólo contemplan personas light o ficticias, es decir, dimensiones sectoriales de los seres humanos que les permiten a ellos — a los teóricos - realizar construcciones lógico-conceptuales en clave de retórica y en menor medida de dialéctica. Aquellas facetas que son tenidas en cuenta excluyentemente y estos razonamientos que excluyen de sus ámbitos lo que no puede ser deducido evidentemente desde las primeras premisas, ocupan el lugar de las personas, y vemos cómo las teorías de la Edad Moderna y de la segunda mitad del siglo XX han creado —desde estas versiones de las personas - un espacio humano siempre homogéneo y uniforme ${ }^{19}$.

Estoy hablando de la uniformidad o de la homogeneidad de los puntos de vista desde los que se analizan y estudian los temas humanos, y de cómo las personas quedamos reducidas a puntos de atribución de las reglas que resultan de jugar con alguna idea de igualdad. El carácter monomorfo que impone la exigencia de la igualdad lleva a desconocer tanto a las personas en general como a las determinaciones propiamente personales, de modo que, finalmente, los problemas teóricos se resuelven gracias una noción del espacio en el que estamos situados los hombres. $\mathrm{El}$ acento argumentativo se desplaza desde las diversas situaciones y vivencias del homme situé a la uniformidad del espacio. Esta homogeneidad les resulta necesaria: si el que teoriza sobre la justicia tiene en cuenta que unas son las obligaciones del profesor cuando conduce su automóvil, otras las que le exige la claridad en sus clases, y otras las que se derivan de su condición de padre de familia, la regla de la igualdad aparece claramente insuficiente; pues la conducción, la docencia y la educatio de sus hijos le lanzan exigencias que no se pueden explicar, en modo alguno, desde la simetría de las diversas partes en estas relaciones.

Han aparecido temas, como las personas y la igualdad, el espacio sin formas, o los condicionantes ontológicos que son propios de la mayor parte de los razonamientos jurídicos. Como apuntan a problemas

19. Locke hablaba de un "Uniforme espacio llano de extensión en donde la mente no encuentra variedad ni marks". Essay of Human Understanding, en "The Works of John Locke”, London, 1823, p. 162.

Facultad de Derecho y Ciencias Sociales - Universidad de Valparaíso - Chile 
excesivamente amplios, hagamos saltar una primera alarma, que parece la más elemental de todas: todos los hombres se resisten a hablar de derechos sin las personas, de modo que ninguna regla implícita en una pragmática formal del lenguaje puede darnos o quitarnos posibilidades lícitas de actuación. Apel —el teórico quizá más paradigmático del Continente- mantiene que hemos de respetar los derechos de los demás para no romper la igualdad; pero es difícil entender cómo una figura matemática, o geométrica, como es la igualdad, puede aspirar a la universalidad —es decir, a poseer una índole propiamente normativa- en el momento de normar las vidas humanas ${ }^{20}$. Cabalmente es imposible hablar de teorías de la justicia sin hundir los razonamientos en las personas, pero es preciso tener a la vista la advertencia clásica: Homines, qui metuunt facilia et sperant impossibilia...

Para hacer posible lo fácil sin esperar cosas imposibles, aparecieron los autores personalistas; pero desde la majestuosa representación de unos seres irrepetibles en la historia, cada uno de los cuales porta en sí la dignidad de toda la humanidad, es difícil hablar de los derechos. John Austin advertía que si los derechos son eternos e inmutables, la ciencia jurídica no tiene nada que decir sobre ellos ${ }^{21}$. Austin no se refería a los filósofos personalistas — en aquel momento desconocidos bajo este título- sino a los que propugnaban los derechos humanos afirmados a comienzos del siglo XIX. Los defensores de las

20. Han caído bajo el dominio de una falacia, que arranca desde una verdad indiscutible: que en situación de simetría, mis derechos han de ser iguales a los derechos de los demás. Pero la actitud de los teóricos de los diálogos ideales implica tasar anticipadamente lo que debemos entender por una persona o un parlante, y establecer ellos las condiciones bajo las que el habla sería verdaderamente ideal. Habermas o Rawls tienen sus prejuicios — de los que no parecen ser conscientes-y exigen a todos que ellos también asuman normativamente estos principios-prejuicios fundados en bases empiristas.

21. Escribía: "But, if the parties ... appealed to unmeaning abstractions or to senseless fictions; if they mouthed of "the rights of man", or "the sacred rights of sovereigns", of "inalienable liberties", or "eternal and immutable justice" ... A sacred or inalienable right is truly and indeed "invaluable": for, seeing that it means nothing, there is nothing which can be measured". Lectures on Jurisprudence or the Philosophy of positive Law, $5^{\mathrm{a}}$ ed., John Murray, London, 1911, Lecture II, p. 119.

Revista de Ciencias Sociales - Número 66 (2015) - Universidad de Valparáíso - ISSN 0716-7725-Valparaíso, Chile 
personas portadoras sin más de derechos, entran normalmente en este grupo tan discutido. Ellos quieren ofrecer una versión general o absoluta del ser humano sin reparar en las funciones de las cosas que nos vinculan, nos separan o nos capacitan; como es lógico, pierden de vista a la ciencia del derecho. No tienen en cuenta la advertencia de Tomás de Aquino cuando explicaba que la persona es solamente el homo larvatus $^{22}$.

Pero no minusvaloremos la corriente personalista, o a la corriente de los que defienden directamente los derechos, porque la representación directa de las exigencias de la dignidad personal ha llevado a crear la seguridad social, o a regular más humanamente el trabajo. En el campo más propiamente jurídico, no siempre reconducible a las grandes reformas sociales, las remisiones a las personas son útiles frecuentemente para evitar el sociologismo; pero frecuentemente ofrecen criterios excesivamente incompletos que han de ser completados por la inesquivable ciencia jurídica.

\section{Igualdad y argumentaciones}

He apuntado que el estudio del derecho se mueve al filo de realidades distintas, ya que uno es el derecho de toda persona a ser tratada igualmente ante las leyes, y otros es el derecho que tienen los alumnos para que su profesor les explique con la claridad adecuada. Obviamente no damos cuenta de esta diversidad si decimos que son derechos distintos; habría que indicar que tienen fundamentos, orígenes o bases distintas, lo que nos lleva al tema - pavoroso para los materialistas - de la heterogenia de los principios prácticos. Pero esta heterogenia ha de ser negada en nombre de la igualdad última de todo lo existente. Una conquista moderna de este estilo de pensamiento ha sido la de imponer la idea de que el derecho consiste en una sola realidad. Efectivamente, el estudioso obtiene la impresión de que los teóricos del derecho de estos últimos siglos que han propuesto teorías sobre la justicia, han girado reiterativamente en torno a la pretensión de ofrecer

22. Vid. In IV Sententiarum (In Primum et Secundum Sententiarum), Tomus Sextus, “Opera Omnia”, Romae, 1570, L. I, Dist. 23, q. 1.

Facultad de Derecho y Ciencias Sociales - Universidad de Valparaíso - Chile 
un único y solitario criterio de la justicia que serviría para guiar a la masa algo informe de normas y principios que compondrían el conjunto de cualquier ordenamiento jurídico. Es lógico que contemplen así este tema, porque desde el siglo XVIII buena parte de la reflexión jurídica ha visto su tema de trabajo en elucidar 'el' concepto del derecho; si sólo hay un único modo de manifestarse la vida jurídica, bastaría una sola receta universal para hacer posible la justicia. Esta actitud porta cierta capacidad para el convencimiento, porque Bergson indicaba que "La materia tiene una tendencia a constituir sistemas aislados que se pueden tratar geométricamente; y es por esta misma tendencia por la que nosotros la definimos". Efectivamente, en la pluma de un materialista, el derecho sería una cristalización del movimiento humano que puede entenderse bajo moldes geométricos. Pero Bergson también reconoce que "La metría no va hasta el fin, y que estos aislamientos no son jamás completos" ${ }^{23}$. No quiso proseguir la objeción contenida en esta segunda observación. Si la hubiera proseguido hubiera ayudado a clarificar la irreductibilidad de los subjets a los criterios clasificadores y de mensura.

(Las 'teorías del derecho' que aparecieron en el siglo XIX, fundamentalmente en los territorios de lengua alemana, llamadas Rechtsphilosophie, Philosophie des Rechts, e incluso Gesetzgebungswissenchaft, aparecieron con esta falta de origen, a saber, que quisieron proporcionar una sola fórmula, fuera el destino entero del hombre (Trendelenburg) o una sociedad de hombres libres (Stammler tardíamente), que resolvería la justicia de todo el ordenamiento jurídico. Pero un orden jurídico se compone de muchas instituciones que sólo tienen en común su cauce final procesal y coercitivo. Fuera de esto, cada relación tiene su propia causa, sea una peculiaridad de origen — pensemos en muchos derechos humanos_- sea una finalidad que socialmente ha de ser alcanzada, y esta génesis no homogénea de los principios constitutivos de cada relación e institución, determina que cada una de ellas tenga sus propias leyes de desarrollo, sea un desarrollo axiomático o inductivo. Fue comprensible que Thomas Erskine Holland las llamara Jurisprudence on the air $)^{24}$.

23. L'évolution créatrice, en “CEuvres”, PUF, Paris, 1959, p. 502.

24. Holland escribía que "From treatises upon 'Naturrecht' which may to describe as 'Jurisprudence on the air' he has derived next to nothing". The Elements of Jurisprudence. $13^{\mathrm{a}}$ ed. Oxford, 1924, p. VIII.

Revista de Ciencias Sociales - Número 66 (2015) - Universidad de Valparáíso - ISSN 0716-7725-Valparáiso, Chile 
Las teorías de una sola solución de Apel o Rawls, son comprensibles porque ellos afirman la existencia de esa materia universal que siempre puede ser unificada desde el punto de vista aritmético o geométrico. Pero retomo la segunda observación de Bergson: no podemos conocer siempre a la materia de una forma completa y esta falta de exactitud es, en los materialistas, una fuente de confusiones que conduce inevitablemente hacia la arbitrariedad en los momentos de diseñar sus correspondientes teorías de la justicia. Los geómetras saben que cuando el teorema a construir parte desde un solo dato, la imaginación, falta de referentes plurales, está en su derecho de dispararse en direcciones distintas y caprichosas, y entonces ellos componen un sistema en el sentido estricto del término. Quizá la nota más típica del sistema sea la indiferenciación de sus partes, ya que sólo reconoce un initium que es simultáneamente el cuerpo argumentado, los razonamientos realizados, y el resultado finalmente obtenido. La falsilla que le sirve al autor de sistemas para interpretar lo que él percibe y crea la expuso Ludwig Knapp en una frase algo lapidaria: "Todo es uno. No hay una diversidad última" 25 .

Es patente que tenemos constructos sobre la justicia que no dan cuenta de la diversidad de las pretensiones de los seres humanos, pero estas construcciones actuales son fácilmente explicables gracias al carácter sistemático que les otorga la lógica desarrollada teóricamente en un solo plano ${ }^{26}$ : sus autores los exponen, y los que los oyen han de asentir gracias a la rigurosa trabazón lógica que muestran estas teorías. Planteada así cada teoría — también las que tratan sobre la justicia-, sólo cabe o el asentimiento a ella, o su rechazo de plano; pues cuando

25. "Alles ist Eines. Es giebt keine letzte Verschiedenheit". System der Rechtsphilosophie, Erlangen, 1857, p. 25. Cito a este filósofo, poco conocido hoy, porque quizá fue quien con más precisión y acribia expuso la filosofía materialista en el siglo XIX alemán. F. González Vicén supo apreciar la calidad de su obra.

26. Descartes exponía claramente esta visión: "Je voudrais chercher, après cela, d'autres vérités, et m'étant proposé l'objet des géomètres, que je concevais comme un corpus continu, en un espace indéfiniment étendu en longueur, largeur, et hauteur ou profondeur, divisible en divers parties". Discours de la méthode, en "CEuvres", Gallimard, Paris, 1953, Quatrième Partie, p. 150.

Facultad de Derecho y Ciencias Sociales - Universidad de Valparaíso - Chile 
una teoría rompe en su inicio, en nombre de su carácter sistemático, con las distintas explicaciones de las conductas humanas, el único recurso que le queda al discrepante es el rechazo total ${ }^{27}$, tal como hace Sócrates con Gorgias. Pues este sofista expone una teoría sistemática, con sus propias bases de arranque y con sus leyes de desarrollo coherentes lógicamente: así planteada, una teoría es invencible. Así es si así seguimos las reglas de este juego: toda teoría sistemática goza de la plenitud que le confiere su carácter autoportante, esto es, el rigor lógico con el que los teoremas se deslizan desde los axiomas elegidos y puestos inicialmente, y no cabe impugnación: sólo puede haber desprecio de un sistema en nombre de otro sistema. Sucede, en definitiva, que el rechazo del conocimiento ontológico o metafísico de las 'cosas' y de las personas impide reconocer algunos criterios de verificación de cada propuesta teórica. Pero es mejor no adelantar tan bruscamente las ideas.

Expresándonos en términos propios de las ciencias exactas, este desarrollo lógico-lineal proviene, quizá, desde el hecho de que los autores de base empirista mantienen que la sola condición formal del conocimiento del espacio material —en nuestro caso el espacio humano representado por alguna tendencia del hombre- es suficiente para crear una antropología y no admiten por ende que las condiciones formales de las síntesis en el derecho tienen fundamentos y desarrollos distintos ${ }^{28}$. Hoy resulta espinoso volver sobre este tema, porque lo cierto es que Descartes identificó la materia con el espacio ${ }^{29}$, y desde la extensión de su obra, todo materialista, también cuando estudia la ética social creando su propio objeto, ha pensado en los términos del espacio plano y polarizado cartesiano, porque, hablando en términos muy generales, el materialismo consiste en la sustitución de las formas por la imaginación de la materia siempre igual, monomorfa y sin relieves ${ }^{30}$.

27. De ahí que hace años, cuando estaba de moda hablar de ideologías, algunos ideología.

explicaran que una ideología únicamente podía ser combatida por otra

28. Referida a la geometría, vid. esta observación en Saumells, La ciencia y el ideal metódico, Rialp, Madrid, 1958, p. 48.

29. Vid. Saumells, La ciencia y el ideal metódico, cit., p. 83.

30. Vid. Saumells, La ciencia y el ideal metódico, cit., p. 190.

Revista de Ciencias Sociales - Número 66 (2015) - Universidad de Valparáíso - ISSN 0716-7725-Valparáiso, Chile 
Pues si examinamos la estructura más íntima del diálogo ideal de Habermas o de la posición original de Rawls, veremos que todo está ya explicado desde el momento en que el lector de sus obras acepta la singular igualdad de los sujetos en ese solar — casi de naturaleza física o espacial y, en cualquier caso prevalentemente de naturaleza visualque es el la posición original o el diálogo inicialmente impuesto ${ }^{31}$. En realidad, no hay diálogo, porque todo coloquio presupone una pluralidad de individuos con pretensiones distintas, y en estas versiones del estado de naturaleza sólo destaca la 'existencia' de la exigencia, siempre monocorde, de la igual libertad.

Es patente que ellos sustituyeron la razón formal de ser de la justicia -utilizo el término formal como adjetivación de la palabra forma- en cada caso por una condición material del espacio sensible (la igualdad de los puntos en el espacio), y quieren deducir aquella desde ésta, como si la igual o idéntica posición geométrica asegurara, partiendo desde cuerpos materialmente iguales, la rectitud de lo decidido. Estos son paralogismos insoportables ${ }^{32}$. Por el contrario, parece preferible exigir construcciones dialógicas cuyo carácter formal y sintético no reconozca como fundamento íntegro y excluyente el ámbito

31. Es comprensible: Bergson indicada que hemos organizado nuestra forma de pensar sobre las formas de los cuerpos inorganizados y, al parecer, nos sentimos desasistidos fuera de este marco de pensamiento. Vid. L'évolution.., cit., p. 506. Es lógico que sea así. El mismo Bergson explica en otros momentos que los cuadros que hacen posible nuestra comprensión son demasiados estrechos y demasiados rígidos para lo que queremos introducir en ellos. Nuestro razonamiento, tan seguro de sí mismo cuando camina sobre cosas inertes, se mueve mal cuando camina sobre un terreno vivo. Vid. op. cit., p. 490. Más adelante, en la p. 632, explica que la lógica natural nace de una cierta geometría natural, sugerida por las propiedades generales percibidas en los sólidos. Desde esta lógica general ha surgido la geometría científica, que extiende indefinidamente los perfiles de los sólidos. Geometría y lógica están indisolublemente unidas a la materia.

32. Se impone la objeción de Bergson cuando indica que sólo hay un medio para refutar el materialismo: establecer que la materia es absolutamente como ella parece ser; así eliminaríamos de la materia toda virtualidad y toda fuerza oculta, y los fenómenos del espíritu tendrían una realidad independiente. Pero sería preciso dejar en la materia todas esas cualidades que materialismo y espiritualismo se empeñan en quitarle. Vid. L'évolution.., cit., p. 219.

Facultad de Derecho y Ciencias Sociales - Universidad de Valparaíso - Chile 
falsamente geométrico en el que se representan. Quienes proponen puntos iguales en un espacio sin formas ${ }^{33}$, y mantienen que estos puntos somos las personas, se incapacitan para entender que, paradójicamente, lo que caracteriza así a las personas es un dato - la igualdad monomorfa del espacio- absolutamente inferior, en todo, a los seres humanos. Quisieron fundamentar valoraciones donde solamente puede haber puntos, líneas o superficies hechas posibles por la conciencia objetiva del geómetra ${ }^{34}$.

Fue lógico que designaran genéricamente a estos constructos como expresiones del mos geometricus. La garantía de su cientificidad vino dada ante todo por el uso de las mismas categorías en las ciencias naturales y en las ciencias humanas, yendo hacia una ciencia unificada ya desde el siglo XVII. Pero lo cierto es que esta uniformidad tan homogénea y tan sin diferencias pagó, a cambio de esta mayor capacidad pedagógica, un precio demasiado alto. De este modo, lo que sólo es una vertiente de la estructura del psiquismo humano fue elevado al rango de criterio discriminador último de la justicia. Lo individual en tanto que individual, fue confundido con la identidad de cada sujeto, y la vieja regla filosófica que fundamentaba la personalidad en la incommunicabilitas recibió un nuevo contenido tan ajeno a la intención inicial como empobrecedor de ella ${ }^{35}$.

Veamos. Decimos que dos cosas son diferentes cuando sus límites no son idénticos. Pero si agrupamos inicialmente todos los objetos que

33. Gent llama al espacio entendido así un "formfreie Zeitmodus". Vid. Die Philosophie des Raumes und der Zeit, Verlag von Friedrich Cohen, Bonn, 1926, vol. I, p. 318 .

34. Roberto Saumells define a la conciencia objetiva como "El ámbito de una cierta forma de presencia propia de los objetos en tanto que están destinados a su conocimiento". La geometría euclídea como teoría del conocimiento, Rialp, Madrid, 1970, p. 32. Descartes prefiere la palabra 'imagination'. Vid. Seconde méditation, en «Euvres et lettres», Gallimard, Paris, 1953, p. 280.

35. Vid. mi estudio Persona, derecho, judicatura, en "El derecho a la justicia imparcial”, F. Carpintero-M. C. Londoño (coords.), Comares, Granada, 2012, pp. 1-40. Disponible en la web franciscocarpintero.com 
queremos conocer o crear sobre una llanura puesta exclusivamente por la razón, tendremos que desconocer necesariamente tanto las diferencias de las personas entre sí como las diversidades entre las personas según las cosas que las relacionan. El carácter monomorfo del espacio ha sido el gran enemigo de la metafísica y de la ontología. Por el contrario, el profesor sabe no solamente que él es una persona distinta e igual en derechos básicos a sus compañeros de trabajo, sino que entiende igualmente que sus obligaciones como conductor de su automóvil son distintas de sus obligaciones como profesor. La resistencia para aceptar la heterogenia de los principios prácticos sólo puede ser entendida como una exigencia, algo infantil, del que pretende que todo y todos se acomoden al plano de la realidad que él ha seleccionado como el único posible.

La geometría sólo conoce figuras que están puestas algo arbitrariamente por la imaginación. El mos geometricus solamente pudo proponer el Nicht-Sein, es decir, figuras que negaban, sustituyéndolas, a las figuras anteriores. Hegel captó este problema y definió al punto como la negación del espacio ${ }^{36}$. Los geometrizantes pusieron en origen un espacio plano a modo de llanura, o esfera como pretendía $\mathrm{Kant}^{37}$. Pero al volver la espalda a las condiciones de síntesis tan formales como concretas y sustituirlas por una única síntesis omniabarcante que hacía posible la intuición de los cuerpos en el espacio (un trasunto de las ciencias de la naturaleza) tanto afirmaron el espacio - como se seguía de la teoría kantiana - como lo negaron, como expresaba Hegel. En esta antítesis constitutiva del espíritu de la Modernidad, las ciencias del hombre en tanto que hombre permanecieron como absurdas, a menos que aparecieran como apéndices de alguna ciencia natural. De hecho, nos ha quedado ante todo un dilema: o se afirmaba universalmente la índole universal del espacio, como hicieron los materialistas, o negaban

36. "Der Punkt, das Fürsichsein ist deswegen vielmehr die und zwar in ihm gesetzte Negation des Raums”. Enzyklopädie der philosophischen Wissenschaften, Suhrkamp, Frankfurt am Main, 1970, “Der Raum”, § 254.

37. En la Crítica de la razón pura, trad. de P. Rivas, Alfaguara, Barcelona, 1988, A762, mantuvo que a razón no es una llanura, sino una esfera.

Facultad de Derecho y Ciencias Sociales - Universidad de Valparaíso - Chile 
los espacios humanos diversos y plurimorfos para afirmar a las personas, como hicieron Kant y sus discípulos, quienes, para designar a este nuevo hombre en el derecho que negaba tanto la síntesis universal formal materialista como las síntesis plurales propias de las determinaciones humanas, acuñaron la expresión de juristische Person ${ }^{38}$. Al final de este proceso sólo permaneció la idea confusa de unos individuos aislados y autónomos que no tenían el deber de aceptar lo existente; solamente su voluntad, siempre en potencia para concluir contratos, podía ser considerada la única fuente de sus obligaciones. Esto implicaba entrar abiertamente por el camino de las ficciones, y Hegel reconoció esta insuficiencia al tratar el momento de las voluntades aisladas que contrataban, en la primera parte de su Filosofía del derecho, a la que llamó "Derecho abstracto".

\section{Las ausencias se mostraron operativas en la geometría social}

Este momento de la explicación abre caminos distintos que reclaman una elucidación, y es preciso elegir uno de ellos descartando a los otros. Puestos a realzar el tema que más interesa, la pregunta que se impone es la de interrogarnos hasta qué punto los sistemas éticos que pudiéramos llamar mecanicistas o binómicos estaban determinados por métodos científicos que hicieron de las ausencias el quicio de su validez. Porque se insinúa la sospecha que insiste en que las limitaciones intrametódicas, que fueron imprescindibles para echar a andar la física moderna, la medicina científica, etc., han sido útiles en sus respectivos ámbitos; pero que el estudio del hombre, siempre pugnando entre su subjetividad individual y pretendidamente infinita y su personalidad igualmente social, no se deja estrechar por esas limitaciones iniciales.

Podría pensarse ingenuamente que las limitaciones y las ausencias no son productivas por sí mismas. No ha sido así, porque la mentalidad del Iluminismo descubrió que toda negación es un arma argumentativa omnipotente, ya que aporta una universalidad — gracias

38. Vid. mi estudio La independencia y autonomía del individuo: los orígenes de la "persona jurídica”, en "Anuario de Filosofía del Derecho" (1987) pp. 477-522. Disponible en la web franciscocarpintero.com

Revista de Ciencias Sociales - Número 66 (2015) - Universidad de Valparaíso - ISSN 0716-7725-Valparaíso, Chile 
a su naturaleza simplemente formal- de aquello que es negado ${ }^{39}$. Y, una vez introducidos por el camino de la universalidad, todo lo que no puede ser negado universalmente, parece reclamar para sí su existencia. Kant, con sus postulados continuos ofreció el ejemplo arquetípico de esta forma de proceder. La negación selectiva semper et ad omnes usos de algunos factores ofrecidos por la experiencia, posibilita la vigencia de la aparente validez positiva —afirmada ahora, sin embargo, con alcance igualmente universal- de los otros factores que el científico exige en las bases de sus explicaciones. Estos teóricos se comportan como los ladrones que desconocen las propiedades de los otros pero que, una vez que ellos parecen ser los propietarios, exigen a todos que respeten lo que presentan como propiedad suya ${ }^{40}$. Con razón escribía Kant, siguiendo la terminología propia de la defensa de las tesis doctorales, Beati possidentes!

De hecho, las negaciones cumplen ante todo la función de ofrecer un magro contexto de justificación del discurso que posteriormente será expuesto. Pero las angosturas epistemológicas entran en la Teoría del Derecho por la puerta grande, porque no tanto aparecen como la expresión de un ignoramus como el fundamento discriminador que determina incondicionalmente la existencia de lo expuesto. La racionalidad, en una versión simplista, nada a gusto en estas aguas. Pues unas veces descalifica universalmente a lo que no le interesa, y en

39. La exclusión de algunas notas o caracteres de la realidad que ha de ser estudiada es siempre peligrosa porque el estudioso ha de cargar con el peso de lo que él suprime. En sede de matemática pura, Frege indica que "Wir müâen uns nur immer genau klar vor den Augen halten, dass es auf eine Bedeutung hier in arithmetischen Spiele garnicht ankommt. Also: wenn eine Sunstrahireng möglich sei, lässt sich gar nicht beurteilen, ehe wir wissen, welche Figuren dabei in Betracht komen können, und was mit ihnen vorzunehmen sei. Das muss uns so genau beschrieben werden, wie das Rochiren im Schaspiele”. Grungesetze der Arithmetik, Georg Olms, Hildesheim, 1962 (1903) vol. II, p. 109. Si los investigadores de la teoría jurídica siguieran este consejo sencillo, y explicitaran qué es lo que realmente suprimen en el momento de definir, muchas explicaciones se vendrían abajo.

40. Todo concepto y todo método necesita un momento negativo, pues conocemos las cosas no sólo por lo que ellas son sino también por lo que no son. Saumells hace notar que toda figura, para poder ser representada, necesita de una anti-figura, de un soporte en el que pueda ser mostrada. Vid. La geometría euclídea.., cit., p. 72.

Facultad de Derecho y Ciencias Sociales - Universidad de Valparaíso - Chile 
otros momentos afirma, también de forma incondicional, lo que quiere imponer. Así ha resultado que las filosofías empiristas — aunque no son las únicas - se han revestido de un carácter dogmático desconocido anteriormente.

Una vez establecido el marco científico tan previo como aparentemente necesario, que es el que dará origen a esas philosophies nécessitaires aludidas, la tarea histórica de los filósofos de base empirista ha consistido en razonar desde los elementos que han pasado los filtros puestos por ellos. No debieran haber insistido negativamente sólo en los datos que dejan pasar sus criterios de justificación sino, más positivamente, en los criterios de validez que son concordes con los datos que es preciso procesar ${ }^{41}$, ya que desde el hecho de que algo no resulte rechazado no se sigue sin más la afirmación positiva de su existencia; además, su adaptación a las restricciones metódicas nos indica poco sobre los fundamentos, alcances y límites de lo que ha sido afirmado. Pues es necesario tener en cuenta lo ya indicado, a saber, que el profesor tiene obligaciones distintas como conductor de automóvil, como enseñante y como padre, de modo que si no se admite la operatividad distinta de cada uno de estos tipos de realidades, el derecho deviene una técnica sencillamente imposible por inexplicable. Pues las instancias solitarias de validez —al modo de las positivistasdeterminan poco y, por el contrario, las exigencias diversas de los datos en que vivimos - y que de hecho todos tenemos en cuenta vitalmenteson las que debieran haber explicado las posibilidades de los criterios de las distintas justificaciones ${ }^{42}$. Pero la historia llevó el tema de otro

41. En este sentido, vid. mi estudio "¿Regla de reconocimiento, o contexto de reconocimiento?, en "El positivismo jurídico a examen. Estudios en homenaje a José Delgado Pinto”, Universidad de Salamanca, 2006, pp. 171-195. Disponible en la web franciscocarpintero.com

42. Savigny explicaba que el derecho consiste ante todo en la invulnerabilidad de cada persona (en el sentido kantiano de este término), desde la que se configuran todos los institutos jurídicos positivos cuyo contenido concreto von jene Unverleztichkeit selbst völlig verschieden ist. Vid., System.., cit., §53, p. 337. De hecho, él hace suyo el dicho romanista que explica que cada hombre es relevante ante los otros hombres por referencia a las cosas, y propone un esquema triádico para explicar las relaciones jurídicas: la propia persona $\rightarrow$ la naturaleza no libre las otras personas: Die eigene Person, = die unfreye Natur, = fremden Personen. Vid. System.., cit., § 53, pp. 333-334.

Revista de Ciencias Sociales - Número 66 (2015) - Universidad de Valparáíso - ISSN 0716-7725-Valparaíso, Chile 
modo, porque en el lugar de las justificaciones distintas y diversas, la conciencia occidental — siempre preocupada por la Unidad — ha buscado un solo plano de justificación.

Ya que estamos introducidos en un asomo de crítica a estos constructos racionalistas en los que los elementos posteriores justifican a los anteriores, y éstos, a su vez, son válidos porque se deducen desde aquellos primeros datos o 'hechos', es aconsejable limitar otra vez la extensión del campo de este estudio y aludir a algunas manifestaciones (es decir, limitaciones) básicas de los axiomas usados, de las estructuras de los teoremas — plagados de elementos ya insilogizados - y de los prosilogismos que hacen avanzar los razonamientos desde una premisa a otra en el interior de cada teoría del derecho. Perdieron de vista la vieja regla que explicita Saumells: "Hay que reconocer que la edificación de una axiomática válida toma en consideración las condiciones de un principio de coordinación previo. No se axiomatiza en el vacío, sino que el principio de síntesis es un elemento dado con anterioridad a la labor metódica axiomatizante" ${ }^{\text {33. }}$

¿Qué es preciso hacer para insistir en el juego algo tramposo de los axiomas, de las conclusiones, y en tantos elementos functores que llevan desde el inicio hasta el final del razonamiento, yendo desde el principio al final y desde el final al principio? De hecho, la regla de la reversibilidad en las teorías científicas fue una de las primeras que estableció Hobbes como la garantía de la cientificidad ${ }^{44}$. Pero, en su afán de pureza metódica, no fue consciente de la ingenuidad de su propuesta, porque si el que axiomatiza insiste en la claridad de los pasos intermedios, es decir, en la determinación clara y sin dudas de los elementos functores que hacen posible llegar a la meta deseada y, una vez alcanzada esa meta, volver al inicio, no hace sino poner aún más al descubierto a los elementos ya insilogizados y, en definitiva, al prosilogismo que le permite ir y venir desde un extremo a otro de la argumentación. Cuando somos conscientes de la acción de este elemento absolutamente operativo, y de cómo expulsa él de su radio de acción a

43. La ciencia y el ideal metódico, cit., p. 53.

44. Vid., entre otros lugares, Elements of Philosophy, London, 1839, pp. 387-388.

Facultad de Derecho y Ciencias Sociales - Universidad de Valparaíso - Chile 
las otras vertientes de la realidad que deberían matizarlo, la demostración pierde su apariencia de rigor y se muestra tal como es, como un entimema con una premisa solitaria: pura analiticidad ${ }^{45}$. Pero nadie puede admitir expresamente esta reducción de espacio argumentativo porque las teorías necesitan ser extensas y algo crípticas, y si se presentaran con sencillez, perderían el empaque que les proporciona prestigio ante tantos universitarios.

A Hobbes, como a todos los empiristas, se le escapa que la fijación clara de los contenidos de los momentos intermedios de una teoría es una empresa que únicamente puede ser llevada a cabo mediante la eliminación de los sentidos y significados de las palabras que no estén ya en la mente del autor desde el momento en que comenzó a exponer su ‘demostración'. Él no propuso una construcción compleja y por ello ocasionalmente contradictoria, que se adaptara a la complejidad de la realidad. Lanzó una tautología: los hombres viven incómodos e inseguros y desean más seguridad y más comodidades: ¿qué hay que hacer para alcanzar esto último? La regla de oro de este nuevo juego ya la conocemos: es preciso exponer claramente el punto de inicio, mostrar la sucesión rigurosa de los teoremas, y llegar claramente — esto es, convincentemente- al final. Para lograr esto es necesario eliminar todo lo que retrase el paso rápido y claro en la sucesión de los argumentos. Pero, ¿es posible la rapidez y la claridad en los temas humanos? Si adoptamos una actitud sistemática sí parece posible, porque, en virtud de las eliminaciones, la base inicial es única y el modelo del discurso parecería igualmente único; pero este discurso no pasaría de ser una chaqueta de papel pintada sobre el papel. Por el contrario, una actitud 'tópica' — pido perdón por el excesivo desgaste de este término — tendría un vuelo bajo e irregular porque se iría adaptando a las irregularidades del terreno, calcula cada paso, camina más rápido en algunos sitios y más lento en otros. No unifica irrealmente el espacio humano.

45. Sobre el carácter analítico de la ciencia nueva, referido a la biología de Buffon, explica Cassirer que "La verdad de la matemática no consiste en otra cosa que en un sistema de proposiciones puramente analíticas, unidas por el vínculo de la más rigurosa necesidad y que, en último término, no hace más que expresar en formas diferentes un mismo y único contenido cognoscitivo". Filosofía de la Ilustración, trad. E. Imaz, FCE, México, 1984, p. 97. 
No existe ese espacio humano uniforme, siempre previo a cualquier otra situación humana, que identifica toda explicación sobre el derecho de forma tan necesaria como arbitraria. Lo procedente es preguntarse si este traspaso de esta categoría geométrica a las ciencias del hombre logra su objetivo, es decir, si es capaz de dar cuenta de la justicia de nuestras acciones tan diferentes. Pues parece obvio que la justicia consiste en enderezar lo torcido, en regar lo seco o en enseñar al ignorante, y éstas son exigencias diferentes unas de otras; se las podría unificar tomando únicamente un sector o alguna faceta de ellas, pero la unificación así conseguida plantearía más problemas que problemas resuelve, porque un investigador que siga el estilo moderno y parta desde una 'posición' única, ha de olvidar que —incluso en el corazón de la actividad política - tenemos ministerios tan distintos entre sí como el de Defensa, Educación o Fomento. Unos individuos abstractos como los que han diseñado Rousseau o Rawls podrían hacerse cargo individualmente, precisamente por su falta de determinaciones (terminología hegeliana), de todos los problemas de Defensa, Educación o Fomento. Pero esto no es posible, ni práctica ni teóricamente. Descendiendo algo en el nivel de la argumentación, vemos que cuando Rusia comenzaba a sovietizarse, Ludwig von Mises explicó que una sola instancia decisoria no podía hacerse cargo de la complejidad del mercado ${ }^{46}$, y la historia le ha concedido la razón. Efectivamente, la incapacidad de una sola instancia, llámesela individuo o teoría, para hacerse cargo de algún aspecto importante de la vida social, es un problema práctico de tal vuelo que necesariamente hay que considerarlo ya un problema totalmente teórico.

\section{La geometría y la mecánica han quedado atrasadas}

Aunque antes hay que examinar si el entramado teórico último que hace posible estos constructos puede ser mantenido hoy, ya que

46. "Los administradores socialistas no pueden saber si la construcción de una nueva línea ferroviaria es más provechosa que la de una carretera. Y una vez que deciden construir un ferrocarril, no pueden saber cuál de las muchas posibles rutas debería cubrir". Gobierno omnipotente (En nombre del Estado), trad. P. Elgoibar, Unión Editorial, Madrid, 2002, p. 91.

\footnotetext{
Facultad de Derecho y Ciencias Sociales - Universidad de Valparaíso - Chile
} 
ellos reposan sobre una visión de la geometría y de la física que está hoy superada. Efectivamente, estos constructos extraen sus nervios principales desde la estructura de la mecánica de la Edad Moderna que culminó en Newton y Laplace, y el éxito de aquella mecánica avaló de hecho el éxito social de este tipo de construcciones. Fundamentada en lo que parecía ser el éxito irresistible de una forma de proceder concreta y determinada para siempre, los autores de los tratados de derecho natural y de filosofía del derecho que se han sucedido desde el siglo XVII a hoy, han negado la pluralidad de las formas y cualidades y han mantenido únicamente los elementos propios del movimiento psicomecánico. Hay que reiterar que se ha tratado de una cuestión de hecho, que ha sido posible por una de esas vinculaciones tan frecuentes en la vida humana. Aunque estamos ante temas de filosofía política y jurídica, con ser estos saberes ante todo concretos, el prestigio de aquellos moldes veteromecánicos ha hecho posible en sede académica — - y sólo en esta sede- prescindir tanto de algunas objetividades éticas ${ }^{47}$ como de la diversidad de formas que ha de tener en cuenta la filosofía práctica. En pocas palabras, los teóricos modernos y contemporáneos han vuelto la espaldas a las realidades del día a día suponiendo que así como en la física la diversidad puede ser reducida a pocas leyes, el conocimiento verdaderamente científico de la política y del derecho ha de ser montado sobre la descripción breve de movimientos psicológicos provocados mecánicamente y, por tanto, predecibles científicamente.

Aquella mecánica ya está hoy superada en cierto modo. No superada en términos absolutos, como si ya no sirviera la geometría de Euclides o la mecánica de Newton, sino superadas como paradigmas que permiten estudiar todo objeto natural posible ${ }^{48}$. Los cambios metódicos han afectado especialmente a las ciencias de la naturaleza, de modo que Euclides fue destronado por Descartes, normalmente

47. Andrés Ollero, de la mano de Luis R. Vigo, alude a esta moral doble. Vid. Derechos humanos. Entre la moral y el derecho, UNAM, México, 2007, p. 240.

48. Heisenberg indica que la física moderna no limita la validez de Newton, sino sólo la aplicabilidad de su sistema de axiomas. Vid. Los nuevos fundamentos de la ciencia, trad. Ma Gimeno, Ed. Norte y Sur, Madrid, 1962, p. 176.

Revista de Ciencias Sociales - Número 66 (2015) - Universidad de Valparáíso - ISSN 0716-7725-Valparaíso, Chile 
enemigo de Galileo, y Newton superó a estos dos investigadores; pero no consiguieron nada definitivo en tono universal porque Maxwell, Planck, Gödel o Einstein hicieron enmiendas tan severas a Newton, que las mecánicas anteriores ha quedado como métodos útiles sólo en ocasiones $^{49}$. El transcurso de la ciencia en el siglo XX ha hecho ver que

49. Tampoco hoy podemos poner de acuerdo a estos últimos investigadores mencionados, porque tienen tanta razón como sinrazón en el establecimiento de sus explicaciones, y nada resolvemos contraponiendo Einstein a Planck. Pretendo indicar que los cambios metódicos — esos esquemas interpretativos que a veces califican o descalifican a los hechos a tener en cuenta según los axiomas puestos por cada teoríahan afectado a la comprensión de la realidad que estudian los físicos, y como un método sucede cronológicamente a otro, y finalmente hemos de combinar a Euclides con Descartes, Newton, y Planck, ha cundido el desánimo sobre las virtualidades explicativas de cada teoría científica. Hemos ido hacia un relativismo que abona ampliamente las tesis de Kuhn o Feyerabend.

El relativismo metodológico actual ha surgido desde la comprobación de las carencias de cada uno de estos métodos, y por ende de su sola relativa fiabilidad. Ha sido lógico que hoy entendamos que la epistemología que hace posible cada ciencia ha nacido desde factores humanos, es decir, desde las distintas posibilidades y desde las distintas limitaciones que aporta el psiquismo según las posibilidades siempre sectoriales —o desde distintos escorzos - del conocimiento del hombre. Todos están de acuerdo en que estos razonamientos metódicos verifican datos aparentemente elementales pero que ya han sido discriminados según los axiomas puestos por cada método: los datos adquieren valor científico ante todo por el método que los realza insertándolos en una explicación determinada y limitada. Un hecho que se complica porque algunos métodos, como el de Einstein no serán nunca ni verificables, y quizá ni siquiera falsables.

Es fácil para cualquiera ironizar con los que se dedican profesionalmente a las ciencias físicas, porque les podrá argumentar que trabajan según unas ciencias en las que no conocen siquiera su método: Planck para el mundo atómico, Newton para el mundo simplemente sublunar, Einstein para temas más amplios. Algunos físicos replican que no se trata de tres métodos, sino de tres lenguajes en el interior de un mismo método, y que el progreso de las matemáticas unificará estos tres lenguajes. Pero lo cierto es que durante el siglo XX las matemáticas han avanzado como en ninguna otra época histórica, y la experiencia muestra que cada vez que un matemático genial aporta algo sobre lo ya conocido, esta nueva explicación fragmenta aún más los conocimientos teóricos sobre la física. Lo claramente cierto es lo que indican hoy prácticamente todos los teóricos de las ciencias naturales: que el investigador no se enfrenta a unos objetos enteramente distintos de él mismo, sino que la ciencia surge desde una interacción del hombre con su entorno. Sobre esto último, denunciando la separación cartesiana entre sujeto que observa y objeto estudiado, vid. Heisenberg, Física y Filosofía, trad. F. Tezanos, La Isla, Buenos Aires, 1959, p. 61.

Facultad de Derecho y Ciencias Sociales - Universidad de Valparaíso - Chile 
los fundamentos de la visión mecanicista y binómica del mundo están periclitados, a pesar de responder al sentido común más extendido, y pocos piensan hoy en la machina mundi, que estaría compuesta por una sola realidad camaleónica que presenta externamente tantas caras. En este punto es indiferente que mencionemos a Newton o a Luhmann. De hecho, el joven Einstein buscó las cosquillas a Newton y publicó su primer estudio sobre problemas de la capilaridad, porque la capilaridad era absurda desde la interpretación mecanicista entonces al uso. Más o menos por el mismo tiempo, diversos estudiosos de la física estaban cuestionando la imagen de la realidad proporcionada por el Iluminismo. Desde comienzos del siglo XX la comunidad científica perdió la fe en la uniformidad de la realidad creada o descubierta según un único método, y la fragmentación metódica — determinada por la desaparición del objeto unitario del estudio- acabó con los sueños universales de la ciencia del siglo XVIII. Lo realmente cierto es lo expresado por Gonseth: el hombre no ha sido nunca tan fuerte como hoy, y nunca han sido tan impenetrables sus conocimientos ${ }^{50}$.

El investigador, que durante estos últimos veinte años ha compartido sus charlas también con profesores de física, de geometría y de matemáticas, ha entrevisto que los físicos actuales saben tan poco de 'eso' que ellos estudian, como el filósofo sobre las ideas, o el sociólogo sobre el sustrato último de las normatividades y regularidades mostradas por los grupos sociales. Al caer de su pedestal la imagen universal uniforme y mecánica, desapareció del marco universitario esa mentalidad difusa que entiende que todos los movimientos solitarios no son sino manifestaciones de una única realidad primera y fundante, de modo que conociendo la en definitiva única ley de ese movimiento, la ciencia podría explicar la estructura monótona de los fenómenos que solicitan la atención del jurista ${ }^{51}$. En otras palabras, es difícil hoy tener

\footnotetext{
50. Vid. Editorial, en “Dialectica” XX (1966) p. 9.

51. Es cierto que si hablamos de la realidad con la generalidad con que Dilthey hablaba de la vida, o Platón y Kant de sus mundos nouménicos, podemos unificar la totalidad de sus movimientos de forma meramente intelectual, atendiendo a un solo posible fundamento de su síntesis formal. Pero esto parece empresa fallida ya antes de comenzarla, porque así sólo lograríamos crear una síntesis tan
} 
fe en un protoelemento que pudiera dar lugar a todo lo que es o existe. Aquella 'última diferencia' negada por Knapp parece haberse convertido hoy en la imposibilidad de un solo método.

Si el autor de estas líneas estuviera convencido de que la explicación del mundo del estilo de Newton es, a pesar de todo (que es el tipo de convencimiento que exhiben algunos universitarios) la necesariamente arquetípica, adoptaría gustosamente una actitud como la de estos empiristas, y contemplaría como se extiende ante su vista una llanura uniforme y amorfa — la del ordenamiento jurídico-cuyas estructuras formales él ha de explicar. Pero el investigador no tiene ese tipo especial de fe que se precisa para creer en esas nociones tan formales y tan lógicamente impecables, porque el derecho es realidad viva, y sus movimientos no componen un templo de cristal siempre transparente por su calidad lógico-formal. Como es lógico, tampoco piensa que los asuntos humanos hayan de ser estudiados de forma igualmente homogénea, esto es, a través de un único método que solamente considere 'cosas' uniformes. Tanto los empiristas como Knapp como los positivistas como Kelsen, propugnaron este modo de proceder porque su materialismo les imponía considerar que todos los fenómenos habían de estar en el mismo plano ¿epistemológico? porque únicamente serían destellos aislados de la única materia o energía existente. Pero si alguien no es materialista no tiene por qué someterse a esta servidumbre.

\section{El hombre se burla de las ciencias naturales}

Reiteramos que las situaciones distintas que vive cualquier profesional le generan deberes y derechos igualmente diversos. Pero estos hechos no arredran a estos teóricos, porque ellos quieren proceder científicamente y la visión moderna de la ciencia da por supuesto un objeto unitario sobre el que ha de recaer la atención del científico. Tal

extremadamente formal y negativa por excluyente, que la realidad contemplada quedaría inexplicada por desfigurada y por sectorial. Los teóricos más relevantes de la física ha sido conscientes de este problema, y Whewell ya advertía, hace más de ciento cincuenta años, del peligro del uso de estas nociones tan generales. Vid. The Philosophy of Inductive Sciences founded upon their History, $2^{\mathrm{a}}$ ed. London, 1847, vol. I. Hay reprint de Johnson, New York, 1967.

Facultad de Derecho y Ciencias Sociales - Universidad de Valparaíso - Chile 
cosa hicieron Newton o Laplace con los átomos, o Bentham cuando teorizó sobre la Jurisprudence de la mano de los intereses humanos ${ }^{52}$.

No podían admitir pluralidades porque entendían que las leyes universales que observaban, o que postulaban cuando no podían observarlas directamente, que eran idénticas para todas las realidades que estudiaban: ésta es una diferencia básica con la mentalidad de los juristas, expuesta algo tardíamente por Alberto Bolognettus, Joachim Hopper o Johannes Althusius ${ }^{53}$. Sucedió que los moderni suponían un singular isomorfismo entre el psiquismo humano y la 'materia' que estudiaban: gracias a tal igualdad de planos, el complejo neuronal del hombre podía penetrar de algún modo en los objetos estudiados, ya fuera en las ciencias naturales ya en las teorías sobre la justicia. Como para los materialistas la formación de estos objetos habría sido casual, violenta y amoral, la cuestión de las finalidades, y en general de las formas o cualidades distintas, estaba fuera de lugar, y la única causa del movimiento a tener en cuenta era lo que los escolásticos llamaban la causa eficiente $e^{54}$ : el científico sólo había de reconocer las impulsiones

52. La importancia de Bentham en la formación de la Jurisprudence fue realzada por John M. Lightwood en The Nature of Positive Law, Macmillan and Co., London, 1883, pp. 57-60. Bryce lo consideraba ante todo un reformador, no un jurista. Vid. Analytical School. The Methods of Legal Science, en "Studies in History and Jurisprudence”, Oxford, 1901, vol. II, pp. 180, ó 183.

53. Vid. A. Bolognettus, De lege, jure et aequitate disputationes, Wittenberg, 1594. Poco antes había sido publicado en el volumen primero del "Tractatus Universi Juris”. J. Hopper, Seduardus, seu de vera jurisprudentia, ad Regem, libri XII, Antwerpiae, 1590. El rey al que está dedicado el libro era Felipe II. J. Althusius, Dicaeologia libri tres. Totum et universum ius, quo utimur, methodice complectens, Frankfurt am Main, 1649.

Aparecieron otras obras en tono que hoy llamaríamos filosófico; si el lector quiere conocerlas, sin afanes de profundidad, puede consultar mi estudio "Mos italicus", "mos gallicus" y el Racionalismo humanista, en "Jus Commune" VI (1977), pp. 108171. Disponible en la web franciscocarpintero.com Más extensamente, vid. el estudio de M. J. Rodríguez Puerto, La Modernidad discutida: 'Jurisprudentia' frente a iusnaturalismo en el siglo XVI. Universidad de Cádiz, 1998.

54. Francisco Suárez, adelantado a la Modernidad en éste como en otros temas, reducía de hecho todas las causas a la causa eficiente: "De efficiente etiam patet, quia sua natura efficit ut res habeat esse quod antea non habebat, et ad hoc per

Revista de Ciencias Sociales - Número 66 (2015) - Universidad de Valparaíso - ISSN 0716-7725-Valparaíso, Chile 
mecánicas, manifestadas de modos distintos, según las leyes de la inercia universal. No disponían de títulos propiamente científicos para apuntalar esta visión de la ciencia, pues — entre otras cosas - la inercia universal no es demostrable, pero su fe en la mejora innegable del conocimiento científico, suplió lo que faltaba en su ciencia.

El imperativismo jurídico cumplió una función decisiva en el momento de homogeneizar todas las manifestaciones del derecho. Si preguntamos sobre el por qué último de la tendencia imperativista que uniformaba las manifestaciones de la vida jurídica bajo el modelo universal de la orden o del mandato, podemos responder con cierta verosimilitud que esto fue así porque los juristas necesitaban - a semejanza de los nuevos físicos- un corpus certum sobre el que trabajar con aire propiamente científico ${ }^{55}$. Varios de los juristas alemanes de comienzos del siglo XIX — aquellos kantianos que historié en "La Cabeza de Jano"- se quejaban de la falta de un estatuto científico definido de la ciencia del derecho, y manifestaban el desprecio y las burlas que otros investigadores lanzaban sobre ellos ${ }^{56}$. El camino metódico a seguir parecía claro: así como los físicos suponían que los fenómenos eran homogéneos porque procedían desde una materia única y por tanto idéntica a sí misma, los estudiosos del derecho imaginaron un mundo de solas voluntades que daban origen a las normas jurídicas. Esta imaginación era útil porque entendían que este mundo era homogéneo — todas las manifestaciones de las voluntades son siempre

se ac directe tendit actus ejus: ergo efficiens est quasi fons et principium per se influens in effectum: quod esse effectus distinctus est ab esse efficientis: ergo tota deffinitio causae proprissime concernit efficienti”. Metaphysicorum Disputationum tomi duo, Coloniae, 1614, Dist. 12, Sect. 3, §3.

55. John Austin, en su afán por encontrar un sustrato o subjectum al que poder referir o apoyar el derecho, explicó —en plena contradicción con el conjunto de su obra- que el derecho, en última instancia, está formado por los commands del gobernante. Vid. Lectures.., cit., pp. 91-79.

56. Vid. una crítica extensa a lo largo de los Juristische Fragmente de J. A. L. Seidensticker, Göttingen, 1802. Fue tal la actitud crítica de Seidensticker, que publicó anónimo este pequeño libro. La obra mencionada, La Cabeza de Jano, fue publicada por la Universidad de Cádiz, 1989.

Facultad de Derecho y Ciencias Sociales - Universidad de Valparaíso - Chile 
idénticas las unas a las otras en tanto que actos de voluntad o realidades elícitas-, y pronto la palabra derecho fue sustituida por la de ordenamiento jurídico, que denotaba en mayor medida la unidad del orden que establecían las leyes; esta tendencia llegó a su máxima expresión teórica con la Reine Rechtslehre de Kelsen. Esta concepción del mundo jurídico presentaba la ventaja de que el derecho podía ser conocido en su conjunto por el ser humano sin grandes problemas, ya que las normas jurídicas pasaban algunos de los filtros de la ciencia; pues, como explicaba Ludwig Knapp, nadie confunde un ferrocarril construido con un ferrocarril simplemente proyectado ${ }^{57}$.

No se ocuparon del estudio del contenido de las normas, tema que entendieron que quedaba abandonado al azar de la razón humana en la historia. Como Kelsen no podía explicar las razones de las conductas concretas contenidas en cada norma jurídica — esto es, de los principios morales, o de utilidad social— recurrió a un ingenuo molde inspirado en los neokantianos de moda a comienzos del siglo $\mathrm{XX}$ : el conjunto de normas que compone el ordenamiento jurídico obliga porque es conocido a través de una categoría del Entendimiento, la del Deber-Ser ${ }^{58}$. Seguía la vieja separación ilustrada (y también la de los kantianos y neokantianos) entre la naturaleza — que era vista como el reino de la causalidad o necesidad ciega - y el mundo humano, que era el reino de la libertad---si es que podemos hablar de libertad en este

57. Vid. System der Rechtsphilosophie, cit., p. 205.

58. Kant no se atrevió a tanto, y estas categorías - la del Ser y Deber ser- no figuraron en sus tablas de principios puros del Entendimiento o Verstand. Kant únicamente estableció, entre otros muchos lugares, que "Los cuerpos son simples fenómenos de nuestro sentido externo, no cosas en sí mismas". En este tipo de declaraciones se refiere exclusivamente a la intuición de los cuerpos en el espacio, tal como los trata la geometría. Crítica de la razón pura, trad. de P. Rivas, Alfaguara, Barcelona, 1988, A 357.

Más específicamente sobre este tema, vid. mis estudios Igualdad y simetría: la selección de los derechos, en J. Saldaña (ed.), "Problemas actuales sobre los derechos humanos: una propuesta filosófica”, UNAM, México D.F., pp. 61-89, y Nuestros utilitaristas malentienden a Kant, en "El pensamiento jurídico. Pasado, presente y perspectiva. Libro Homenaje al Prof. Juan José Gil Cremades”, El Justicia de Aragón, Zaragoza, 2008, pp. 141-166. Disponibles en la web franciscocarpintero.com

Revista de Ciencias Sociales - Número 66 (2015) - Universidad de Valparáíso - ISSN 0716-7725-Valparaíso, Chile 
contexto doctrinal materialista. Realmente, en este tema inicial, Kelsen innovó poco más allá de los kantianos que estaban a caballo entre los siglos XVIII y XIX.

Pero esta presentación de la realidad jurídica presenta reparos, y de hecho lleva a dificultades metódicas que molestan demasiado al estudio de las facetas de las personas. Por ejemplo, algunos investigadores mantienen que "tras la crítica kantiana a la cosa en sî" (que es el tópico en el que se refugian frecuentemente los que niegan el conocimiento de las vertientes semánticas de las regulaciones jurídicas) no podemos saber lo que es el hombre como persona, ni admitir cualquier dato que nos introduzca en las vertientes ontológicas de sus acciones ${ }^{59}$. Pero ya indiqué que Kant se ocupó expresamente de excluir al derecho de estas limitaciones en A43-44, al escribir que "El concepto de derecho, del que el entendimiento sano hace uso, contiene indudablemente todo lo que la especulación más sutil es capaz de desarrollar a partir de él, pero en el uso común y práctico no se tiene conciencia de las diversas representaciones incluidas en este pensamiento. Por ello no puede decirse que el concepto común sea sensible ni que contenga un mero fenómeno, ya que el derecho no puede manifestarse, sino que tenemos su concepto en el entendimiento y representa una propiedad (la propiedad moral) de las acciones, una propiedad que pertenece a éstas en sí mismas. Por el contrario, la representación de un cuerpo en la intuición no contiene absolutamente nada que pueda pertenecer a un objeto en sí mismo, sino simplemente el fenómeno de algo y el modo según el cual ese algo nos afecta" ${ }^{60}$.

Por otra parte, este modo de proceder tampoco encuentra apoyo en las nuevas metodologías científicas; los métodos de la física que prometían versiones filosóficas y comprehensivas de lo existente, mostrando su necesidad según solamente las leyes causales, han pasado. En cambio, el ser humano ha permanecido como una realidad extraña

59. Vid. el estudio de J. Muguerza (ed.) El fundamento de los derechos humanos, Debate, Madrid, 1998. La mayor parte de los autores que componen este estudio niegan la posibilidad de afirmar que el hombre es un ser personal. El propio Muguerza se mueve en ambigüedades.

60. Sigo la traducción de la Crítica de la razón pura de P. Rivas, ya indicada.

Facultad de Derecho y Ciencias Sociales - Universidad de Valparaíso - Chile 
en los esquemas de los físicos, y las aproximaciones intelectuales para la explicación o explicaciones de sus conductas siguen más bien impertérritas, porque sus conductas no son explicables desde los esquemas más básicos de los empiristas o de los actuales sistémicos. Estas líneas no implican afirmar que podemos conocer un orden del ser objetivo, etc. Solamente indican que no disponemos ya de razones para mantener en la explicación del derecho un escepticismo científico general del tipo del de Hume.

El ser humano permanece a través de los métodos diversos ideados para explicarlo por el mismo hecho que indican los geómetras, que distinguen entre un espíritu científico, que lleva hacia la razón de ser de un teorema, y el espíritu demostrativo, que es el cauce elegido, siempre algo discrecionalmente, para encauzar el desarrollo teoremático propio de todo método. El hombre aporta ambos planos, el científico y el demostrativo. Pero su racionalidad, llevada por el ideal científico, cuestiona una y otra vez las distintas razones demostrativas que idea la comunidad científica en cada momento. Saumells explica que para construir las catedrales antiguas los artesanos fabricaban soportes de madera sobre los que colocaban las piedras que componían la cúpula; una vez acabada ésta, retiraban los soportes ya inútiles; lo que implica que el estatuto de la construcción es realidad distinta del estatuto de lo construido $^{61}$. Tenía razón Wittgenstein cuando indicaba en el último parágrafo de su "Tractatus", que los razonamientos propuestos por él eran como una escalera de la que podíamos prescindir una vez llegados a nuestro término ${ }^{62}$. Tomás de Aquino captó lúcidamente este tema, es

61. Vid. La geometría euclídea.., cit., p. 77.

62. Los científicos intuitivos, al margen del carácter epigonal, siempre han sentido este hecho. Saumells, por ejemplo, indicaba que en el fondo del teorema aparece un conflicto que el especialista explica en términos de una necesidad contrapuesta a una imposibilidad. Vid. La ciencia y el ideal metódico, cit., pp. 63-64. Más adelante en esta obra, en la página 204, alude a la razón más íntima de esta conciencia: "El interior mismo de todo acto de conocimiento comporta una escisión entre percepción y apetito, entre reflexión y libertad. Toda forma de patencia consciente se escinde en actual y posible”. El investigador siempre vivencia una desproporción entre los resultados a que ha llegado y el método que ha seguido: el método siempre le resulta pobre.

Revista de Ciencias Sociales - Número 66 (2015) - Universidad de Valparaíso - ISSN 0716-7725-Valparaíso, Chile 
decir, la diferencia entre la razón científica y la razón simplemente demostrativa, cuando estableció que es tal la diferencia entre las proposiciones generales y las conclusiones concretas, que es preciso suponer que el hombre dispone de dos entendimientos distintos para juzgar sobre cada una de ellas ${ }^{63}$.

Es preciso dar cuenta de la pluralidad de los conocimientos, que se expresan en buena medida en la diversidad de los métodos. No es ningún secreto que la ciencia natural actual está montada sobre la interacción del hombre con su entorno ${ }^{64}$, y que incluso el término interacción ha de ser sustituido por el plural de interacciones, ya que un mismo físico ha de seguir métodos inconciliables pero todos ellos igualmente útiles para estudiar de formas más completas la misma realidad $^{65}$. Ningún investigador puede pretender exponer la verdad absoluta de su visión del objeto estudiado, porque las nociones formales que operan en toda ciencia, trabajan de un modo - igual en la física como en el derecho- que podríamos llamar imprecisamente dialéctico o, quizá con más precisión, tópico. Sucede que ante la lógica puramente binómica, las cosas son o no son; si las 'cosas' solamente existen cuando funcionan - uno de los argumentos más básicos de Kant en su Dialéctica Trascendental - las categorías lógicas se proyectarían sobre lo percibido normándolo sin residuos o excepciones ${ }^{66}$; y si queda algo

63. El de Aquino se ocupó reiteradamente de este tema en Suma teológica, I-II, q. 14. art. 3, en el Liber de Veritate Catholicae Fidei contra errores infidelium seu "Summa contra Gentiles", Marietti, Torino-Roma, 1961, §§ 475 y 1247, en In decem libros Ethicorum Aristotelis ad Nichomachum expositio, Marietti, Torino-Roma, 1964, § 246. $§ 118$ y 1115.

64. Werner von Heisenberg destacaba este hecho destacando que la estructura de la ciencia, hoy, consiste en deducir lo particular desde lo general. Vid., entre otros muchos lugares, Física y Filosofía, trad. F. Tezanos, La Isla, Buenos Aires, 1959, p. 144. La imagen de la natura en la física actual, trad. G. Ferraté, Seix Barrall, Barcelona, 1967, p. 29.

65. Vid. Heisenberg, Los nuevos fundamentos.., cit., p. 44.

66. Un hecho histórico especialmente ejemplar de esta exigencia fue la discusión decimonónica sobre las lagunas en el derecho. Zitelmann hubo de ocuparse de examinar trabajosamente el derecho positivo para mostrar lo evidente: que, al menos, existen regulaciones jurídicas que no acaban de ser completas de acuerdo con sus propios planteamientos. Es una cuestión que hoy nos parece ridícula, pero que muestra hasta qué punto las mentes se dejan arrastrar por las modas académicas.

Facultad de Derecho y Ciencias Sociales - Universidad de Valparaíso - Chile 
sin explicar, el lógico declara que esas cosas inexplicables constituyen aporías. El proceder tópico o dialéctico, más ajustado a los derroteros de la matemática, la geometría o la física actuales, muestra que las nociones formales no gozan de lo que usualmente se entiende como validez 'universal'; simplemente, a veces han de ser aplicadas, y a veces no.

Podría parecer que hoy es ociosa la crítica a la unidad o uniformidad científica, porque la Edad Posmoderna insiste en la fragmentación de lo existente y por tanto de la razón que lo conoce (Lipovetski), en el pensamiento débil (Vattimo), o en la derrota de la razón (Finkielkraut). Pero también estas propuestas siguen el ritmo de los tiempos, según la moda académica exhibida ahora fundamentalmente por Luhmann; desde luego, el diálogo actual lo es con Luhmann, o tendrá poca relevancia. No sucede que Luhmann sea enteramente original, pues ha radicalizado algunas tesis de Bertalanffy en un lenguaje convincente para quien ya esté dispuesto a dejarse convencer por una actitud materialista. Pero, ¿̇las teorías sistémicas se dirigen realmente a resolver fragmentaciones, o complejidades? Porque estos autores sistémicos hablan continuamente de 'reducir la complejidad', y hoy todo conjunto conceptual que ayude en tal empresa reductiva es visto con buenos ojos. Sin embargo, no cabe hablar de tal complejidad en las teorías sistémicas, porque estas teorías no reconocen ni la pluralidad ni, en consecuencia, la complejidad: ellas solamente tienen ante la vista a un misterioso elemento - $\tan$ misterioso como omniabarcante- que reacciona de formas binómicas a los estímulos del entorno de acuerdo con la información de igual naturaleza (siempre el binomio) que posee en ese momento cada sistema ${ }^{67}$. Henri Bergson denunciaba este pensamiento biológico-mecanicista que se encarga de hacer coincidir la adaptación pasiva del milieu y la adaptación activa del organismo ${ }^{68}$. Permanecen bajo el antiguo mito materialista que insiste en la unidad

67. Vid. Luhmann, Complejidad y Modernidad: De la unidad a la diferencia. Trad. J. Beriain y J.M. Blanco, Trotta, Madrid, 1998, pp. 59-62.

68. Vid. Matière et mémoire. Essai sur la relation du corps à l'esprit, en «Euvres», PUF, Paris, 1959, p. 555.

Revista de Ciencias Sociales - Número 66 (2015) - Universidad de Valparáíso - ISSN 0716-7725-Valparaíso, Chile 
de lo existente, tanto en su constitución como en las estructuras de sus funcionamientos, únicamente diferenciadas por el más y el menos.

Sin embargo, complejidad, en estos casos, es sinónimo de riqueza. Sócrates, a su modo tan intelectual, se hizo cargo de la riqueza de la que participa el hombre y, en su humildad, asintió ante un mundo que él no podía explicar pero que había de reconocer. Los moderni invirtieron este proceso entre la realidad y el hombre y reinventaron una versión de la fábula de Esopo sobre la zorra y las uvas: como ellos no podían explicar, negaron. Y, de este modo, la riqueza que permitía argumentar se convirtió en la misma enemiga de lo que debía ser argumentado.

\section{Se abre un momento más positivo: los movimientos distintos de las personas}

Si no aceptamos la sola ley del único movimiento siempre igual, abandonamos la Mecánica y entramos por los campos de la Biología. No es lícito hablar del movimiento en general, porque este concepto implica una abstracción excesiva ${ }^{69}$. Esta noción unitaria fue discutida — en tanto que unitaria — antes de comenzar la Edad Moderna. Platón se inclinaba por un Cosmos ordenado de acuerdo con un plan único, siempre de arriba a abajo. Pero Aristóteles sólo reconocía seres concretos que devienen ellos haciendo realidad las formas de sus movimientos; la explicación de Aristóteles no pretendía ser una teoría de la naturaleza en su conjunto, ni del elemento común a todas las cosas, sino una teoría de las naturalezas de las cosas individuales, es decir, de los movimientos que son propios de cada ser. En este plano de la ética son ciertas dos cosas: que la persona es la titular última de sus acciones, y que estas acciones son realmente distintas porque responden a movimientos distintos de los mismos hombres. No se trata de aludir a los movimientos distintos de las distintas personas, sino a los diversos movimientos necesarios en cada mismo ser humano de acuerdo con las finalidades de las cosas a las que tiende con los derechos que él exhibe en cada

69. Tomás de Aquino explicaba que no podemos hablar de la vida, porque así como la carrera no es distinta del acto mismo de correr, la vida es lo mismo que los actos de vivir. Vid. Suma teológica, I, q. 18, art. 2.

Facultad de Derecho y Ciencias Sociales - Universidad de Valparaíso - Chile 
actuación. Personalidad y diversidad se funden: no podemos pensar en el derecho en una pluralidad de movimientos vitales sin personas, ni en personas sin movimientos plurales.

Hablo de ocultamiento de la variedad que es hecho posible gracias a aquellas primeras limitaciones puestas en virtud del método, porque si la racionalidad que de hecho está en la base de cualquier metodología científica muestra que no coinciden el método que trata de normar la recepción cognoscitiva de las experiencias, y las experiencias mismas, el espíritu científico ha de imponerse sobre el momento simplemente metódico. El científico es siempre un investigador vinculado al material duro que él ha de explicar fatigosamente; el hecho de que él supere a veces las explicaciones anteriores, y que a su vez sus explicaciones hayan de estar abiertas para ser superadas por otras, no quita un ápice de verdad a esta realidad. La imposición del ámbito científico sobre el metódico hace que el deseo de saber del estudioso no quede nunca satisfecho, porque los desarrollos teoremáticos nunca están a la altura de sus conceptos, ni siquiera a la altura del método; el investigador sabe que ha llegado hasta el final, y que ha conseguido la demostración, pero no acaba de entender la razón de su discurso ${ }^{70}$. El instinto científico del hombre lleva a los hechos

70. Así, Saumells, La geometría euclídea.., cit., p. 18. Esto explica por qué, aun usando un mismo método, los resultados son distintos; pues, pese a encuadrarse en el ámbito 'positivista', las doctrinas de Bergbohm, Nawiasky, Kelsen o Hart son diferentes. Fue lógico que Tomás de Aquino, siempre intuitivo, explicara que en las demostraciones, conocemos sin comprender: Vid. Sum. Gent., §2323, entre otros lugares de su obra. Ésta incapacidad para razonar sin acabar de entender es una comprobación ampliamente teorizada. Toda persona que razona, capta, en el acto concreto de razonar, que su razón se encuentra siempre solicitada en dos sentidos diferentes: la comprensión de la razón metódica o demostración, y la comprensión de la razón de ser del problema. Como no es posible satisfacer ambos extremos, el investigador siempre queda con una necesaria sensación de insatisfacción, porque en lugar de encontrar y seguir el dinamismo puro de las ideas que aporta, es consciente de que sólo tiene ante su vista algunas intuiciones intelectuales, en comparación con las cuales, su discurso presenta un aspecto deficiente. Sobre este tema, en geometría, vid. Saumells, La ciencia y el ideal metódico, cit., pp. 78 y 97. De forma más radical, explicitaba en la p. 15 de esta obra que la característica deficiente de todo método consiste en que tiende por sí mismo a excluir el proceso que él funda y posibilita.

Revista de Ciencias Sociales - Número 66 (2015) - Universidad de Valparáíso - ISSN 0716-7725-Valparaíso, Chile 
hacia esas figuras que son medidas; pero una vez efectuadas las comprobaciones, vemos que toda regla de mensura trasciende aquello que es mensurado; en realidad, trasciende a todo el proceso de medir: tal es la artificiosidad de las mediciones y de los elementos utilizados en ellas.

Sin duda alguna, nadie puede pretender que su explicación esté libre de impugnaciones, pero obtenemos un campo común, más de entendimientos que no de disensiones, si permanecemos fieles a la cotidianidad jurídica nuestra, esto es, al derecho positivo y a las nociones y a la protheoria que animan a las manifestaciones de la vida jurídica en sus nacimientos y alcances. Tenemos el derecho de preguntarnos para qué sirve - y por tanto de donde proviene- el fundamento jurídico operativo del poder del padre sobre sus hijos, del capitán sobre su barco, el del policía sobre los ciudadanos, el del acreedor sobre el deudor, y si no lo hiciéramos abdicaríamos de nuestra condición racional. No es un problema de considerar residuos jusnaturalistas o metafísicos, sino de fidelidad al derecho que usamos cotidianamente, que hemos de explicar según categorías racionales, no fingidas o postuladas por falta de explicación convincente. Hay una justicia ya dada, pre-teórica - tema en el que insistió MacIntyre hablando de los conceptos normativosque antecede necesariamente a la reflexión ética ${ }^{71}$. Porque cada poder jurídico o moral no puede ser sino la función de una necesidad concreta, y si un poder práctico — es decir, en el marco de la filosofía prácticano sirve a la resolución de una necesidad humana, entonces la razón manda que se lo considere prepotencia.

71. En su obra más conocida, Tras la virtud, trad. A. Valcárcel, Crítica, Barcelona, 1987, en p. 83, sienta reiteradamente su tesis básica: "El uso de hombre como concepto funcional es más antiguo que Aristóteles y no deriva inicialmente de la biología metafísica de Aristóteles. Radica en las formas de la vida social ... Con arreglo a esta tradición, ser un hombre es desempeñar una serie de papeles, cada uno de los cuales tiene entidad y propósitos propios: miembro de una familia, ciudadano, soldado, filósofo, servidor de Dios". Expone sus explicaciones sobre el "concepto funcional" en las páginas 81 y siguientes de esta obra, e insiste frecuentemente (ver, por ejemplo pp. 254-255), en el carácter intencional de las acciones que hace que el concepto de acción sea secundario respecto al de acción inteligible.

Facultad de Derecho y Ciencias Sociales - Universidad de Valparaíso - Chile 
Estamos ante un tema difícil ante los razonamientos, porque la tendencia a la reductio ad unum es uno de los pilares básicos de la metafísica vulgar de la mente humana ${ }^{72}$. Pero no existe ese denominador común que permita explicar el derecho desde un solo ángulo teórico porque, como expresa el Eclesiastés, uno es el tiempo para reír y otro el tiempo para llorar. El derecho consiste en funciones de las necesidades humanas diversas ${ }^{73}$, y una doctrina que presuponga tout court la unidad del ordenamiento jurídico quedará desbordada por la diversidad de las cualidades emergentes que presenta nuestra vida $^{74}$. Cada praxis vital

72. Bergson reconocía este hecho psíquico y explicaba la tendencia de la inteligencia hacia la unificación. Él indicaba que ésta es una tesis de alcance muy vago que introduce uniformidad en lo que realmente es una multitud de fenómenos. Vid. Matière et mémoire.., cit., p. 624.

73. Por función entiendo, por ejemplo, lo que expone G. Frege: "Funktion von 'x' einen mittelst der Bezeichnungen der Summe, des Products, der Potenz, der Diferenz u.s.w.”. Grungesetze der Arithmetik, Georg Olms, Hildesheim-New York, 1962, p. 5. La noción de función es, como podemos observar, ante todo positiva, porque mienta potencias, fuerzas, diferencias, capacidades, etc. El lector puede encontrar digresiones interesantes sobre las virtualidades de las funciones en la investigación social en la obra de A. Polaino-Lorente Antropología e investigación en las ciencias humanas, Unión Editorial, Madrid, 2010. También en mi estudio La crisis del Estado en la Edad Posmoderna, Thomson-Aranzadi, Cizur Menor, 21013.

Obviamente, no cabe la noción de función de N. Luhmann, que la entiende como un esquema con el que orientan las averiguaciones y valoraciones de prestaciones alternativas. Vid. Fin y racionalidad en los sistemas sociales, trad. J. Nicolás Muñiz, Editora Nacional, Madrid, 1983, p. 30. Más adelante en esta misma obra, página 215, habla de averiguaciones y prestaciones funcionalmente equivalentes. Esto no puede ser real: ni hay sólo alternativas, ni las comparaciones y valoraciones se realizan sobre términos funcionalmente equivalentes.

74. Aunque la teoría de la Gestalt provino más del ámbito de la psicología que no de la biología, reparemos ahora en que los biólogos repararon en el hecho de que cuando convive o se relaciona un grupo de individuos, resultan pautas de comportamiento necesarias en ese grupo que no pueden ser explicadas desde la morfología, etc. de cada uno de los individuos. Llamaron cualidades emergentes (Gest alten) a este tipo de necesidades. Me sumo a la observación de Gehlen: "Un ser constituido físicamente de tal modo que sólo puede vivir si actúa; con eso hemos dado la ley estructural de todas las realizaciones humanas, desde las somáticas a las espiritua les”. El hombre. Su naturaleza y su lugar en el mundo, trad. Fernando-Carlos Vevia, Sí-

Revista de Ciencias Sociales - Número 66 (2015) - Universidad de Valparaíso - ISSN 0716-7725-Valparaíso, Chile 
tiene su propia identidad, que se manifiesta en el derecho en la coordinación interna de estados de cosas, que quedan reflejadas en las instituciones jurídicas: cuando Savigny agrupó al derecho privado en torno a instituciones y no bajo una jerarquía de normas, procedía con mano experimentada ${ }^{75}$. Es cierto que los teóricos del lenguaje — ¿ ¿queda ya alguno que proceda como Quine o Strawson? - hablarán de la simple diferencia entre distintos juegos lingüísticos; pero estos juegos no se constituyen en su identidad propia por relaciones lógico-causales entre ellos, sino — explica Viola_ - "por relaciones de algún modo impenetrables" ". No existe una igualdad de la diversidad, de forma que las diversidades puedan ser agrupadas unitariamente desde algún respecto relevante que escapa a la mirada del común de los hombres y que sólo es accesible al sabio que elabora teorías sobre la justicia. Ya indiqué que quien repare en que las razones que hay que dar a un marido que adultera, a un policía que admite sobornos o a una persona que no trabaja han de ser razones necesariamente distintas, estará en condiciones de entender esta explicación. Porque, explicaba Karl Mannheim, "No hay libertad real en abstracto. A cada control pertenecen ciertas clases de libertades y de restricciones. La libertad del militar es distinta a la del fraile, la del maestro es distinta a la del discípulo, la del padre dentro de la familia es distinta de la que disfruta entre sus compañeros de negocios" $" 77$.

gueme, Salamanca, 1980, p. 26. Añade en la p. 37 que sólo partiendo de la idea de ser práxico, no terminado, entra en el campo la fisis del hombre. La definición como 'ser espiritual' sola no permite nunca ver claramente una conexión entre el estado corporal y lo que se suele llamar razón o espíritu”.

75. Es difícil hablar con rotundidad al referirse a Savigny, ya que es un autor francamente paradójico, sobre el que es difícil sentar alguna opinión con pretensiones de exclusividad. Vid. algunas matizaciones a lo indicado arriba en los capítulos de Kieffner y Wilhelm, en Blüdorn und Ritter (ed.) Philosophie und Rechtswissenschaft. Zum Problem ihrer Beziehungen im 19. Jahrhundert, Vittorio Klostermann, Frankfurt am Main. 1969.

76. De la naturaleza a los derechos. Los lugares de la Ética contemporánea, trad. V. Bellver, Comares, Granada, 1998, pp. 139-140.

77. Libertad, poder y planificación democrática, trad. M. Morán, FCE., México, 1982, p. 36.

Facultad de Derecho y Ciencias Sociales - Universidad de Valparaíso - Chile 
Sucede, en última instancia, que el término 'realidad' posee en las ciencias naturales un significado y alcance que es excesivamente distinto de lo que podemos llamar la realidad o mejor, las realidades humanas. Su uso indiscriminado en ambos contextos es excesivamente equívoco.

Contesto a la pregunta planteada al comienzo del estudio: $\dot{\mathrm{La}}$ ciencia jurídica puede prescindir de los datos que le ofrece la realidad, más allá de un sociologismo o normativismo? ¿Es posible dejar de lado esa realidad máximamente metafísica que es la cualidad personal del ser humano? Han ido emergiendo observaciones que ayudan a cuestionar estas negaciones metódicas.

\section{Bibliografía citada:}

ALTHUSIUS, J.: Dicaeologia libri tres. Totum et universum ius, quo utimur, methodice complectens, Frankfurt am Main, 1649.

AUSTIN, J.: Lectures on Jurisprudence or the Philosophy of positive Law, $5^{\text {a }}$ ed., John Murray, London, 1911.

BEKKER, I.: Das Recht als Menchenwerk und seine Grundlagen, Carl's Winter, Universitätsbuchhandlung, Heidelberg, 1912.

BERGBOHM, C.: Das Naturrecht der Gegenwart, Leipzig, 1892.

BERGBOHM, C.: Jurisprudenz und Rechtsphilosophie. Leipzig, 1892.

BERGSON, H.: Lévolution créatrice, en «Euvres», PUF, Paris, 1959, p. 502.

BERGSON, H.: Matière et mémoire. Essai sur la relation du corps à l'esprit, en «Euvres», PUF, Paris, 1959.

BOLOGNETTUS, A.: De lege, jure et aequitate disputationes, Wittenberg, 1594.

CARPINTERO BENÍTEZ, Fr.: Nuestros utilitaristas malentienden a Kant, en "El pensamiento jurídico. Pasado, presente y perspectiva.

Libro Homenaje al Prof. Juan José Gil Cremades”, El Justicia de Aragón, Zaragoza, 2008, pp. 141-166.

CARPINTERO BENÍTEZ, Fr.: ¿Regla de reconocimiento, o contexto de reconocimiento?, en "El positivismo jurídico a examen. 
Estudios en homenaje a José Delgado Pinto", Universidad de Salamanca, 2006.

CARPINTERO BENÍTEZ, Fr.: La crisis del Estado en la Edad Posmoderna, Thomson-Aranzadi, Cizur Menor, 2013.

CARPINTERO BENÍTEZ, Fr.: La independencia y autonomía del individuo: los orígenes de la "persona jurídica", en "Anuario de

Filosofía del Derecho" (1987) pp. 477-522.

CARPINTERO BENÍTEZ, Fr.: La ley natural. Historia de un concepto controvertido, Encuentro, Madrid, 2008.

CARPINTERO BENÍTEZ, Fr.: Persona, derecho, judicatura, en "El derecho a la justicia imparcial”, F. Carpintero-M. C. Londoño (coords.), Comares, Granada, 2012.

CASSIRER, E.: Filosofía de la Ilustración, trad. E. Imaz, FCE, México, 1984.

CORTINA, A.: Razón comunicativa y responsabilidad solidaria. Ética y política en K.O. Apel, Sígueme, Salamanca, 1985.

DESCARTES, R.: Seconde méditation, en «Euvres et lettres», Gallimard, Paris, 1953.

DESCARTES, R.: Discours de la méthode, en «Euvres», Gallimard, París, 1953.

FALCK, N.: Juristische Encyclopädie, Kiel, 1821.

FEUERBACH, P. J. A.: Über Philosophie und Empirie in ihrem Verhältnis zurpositiven Rechtswissenschaft, Frankfurt/Main, 1869 (Landshut, 1804).

FREGE, G., Grungesetze der Arithmetik, Georg Olms, Hildesheim-New York, 1962.

GEHLEN, A.: El hombre. Su naturaleza y su lugar en el mundo, trad. Fernando-Carlos Vevia, Sígueme, Salamanca, 1980.

GENT, W.: Die Philosophie des Raumes und der Zeit, Verlag von Friedrich Cohen, Bonn, 1926.

GONSETH, F.: Editorial, en "Dialectica” XX (1966).

GONSETH, F.: Mon itinéraire philosophique, "Dialectica” XX (1966) pp. 419 y ss.

GONSETH, Ferdinand: La géometrie et les problèmes de l'espace, Dunond Éditeur (París)—Éditions du Griffon (Neuchâtel), Neuchâtel, 1955, vol. VI.

Facultad de Derecho y Ciencias Sociales - Universidad de Valparaíso - Chile 
HEGEL, G. W. Fr.: Enzyklopädie der philosophischen Wissenschaften, Suhrkamp, Frankfurt am Main, 1970.

HEISENBERG, W.: Física y Filosofía, trad. F. Tezanos, La Isla, Buenos Aires, 1959.

HEISENBERG, W.: La imagen de la natura en la física actual, trad. G. Ferraté, Seix Barrall, Barcelona, 1967.

HEISENBERG, W.: Los nuevos fundamentos de la ciencia, trad. $\mathrm{M}^{\mathrm{a}}$ Gimeno, Ed. Norte y Sur, Madrid, 1962.

HOBBES, Th.: Elements of Philosophy, London, 1839, pp. 387-388.

HOLLAND, Th. E.: The Elements of Jurisprudence, $13^{\mathrm{a}}$ ed. Oxford, 1924.

HOPPER, J.: Seduardus, seu de vera jurisprudentia, ad Regem, libri XII, Antwerpiae, 1590. El rey al que está dedicado el libro era Felipe

II.

JELLINEK, G.: Das Recht des modernen Staates, Erster Band, Allgemeine Staatslehre, Berlin, 1900.

JHERING, R.: Der Zweck im Recht, Leipzig, 4ª ed., 1904, vol. II, p. 135.

JHERING, R.: Die geschitliche-gesellschatlich Grundlagen der Ethik, en "Jahrbuch für Gesetzgebung, Verwaltung und Volkswirtschaft" (conocidos comúnmente como los Smoller's Jahrbücher) 6. Jahrgang, 1882, Erstes Heft.

KANT, I.: Crítica de la razón pura, trad. de P. Rivas, Alfaguara, Barcelona, 1988.

KELSEN, H.: Die Grundlage der Naturrechtslehre, en "Österreiche Zeitschrif für öffentliche Recht”, XIII, pp. 1-37.

KIEFFNER y WILHELM, en Blüdorn und Ritter (ed.) Philosophie und Rechtswissenschaft. Zum Problem ihrer Beziehungen im 19.

Jahrhundert, Vittorio Klostermann, Frankfurt am Main, 1969.

LIGHTWOOD, J. M.: The Nature of Positive Law, Macmillan and Co., London, 1883.

LOCKE, J.: Essay of Human Understanding, en "The Works of John Locke", London, 1823.

LUHMANN, N.: Fin y racionalidad en los sistemas sociales, trad. J. Nicolás Muñiz, Editora Nacional, Madrid, 1983.

Revista de Ciencias Sociales - Número 66 (2015) - Universidad de Valparáíso - ISSN 0716-7725-Valparaíso, Chile 
MACINTYRE, A.: Tras la virtud, trad. A. Valcárcel, Crítica, Barcelona, 1987.

MISES, L.: Gobierno omnipotente (En nombre del Estado), trad. P. Elgoibar, Unión Editorial, Madrid, 2002.

MUGUERZA, J.: (ed.) El fundamento de los derechos humanos, Debate, Madrid, 1998.

BRYCE, J.: The Methods of Legal Science, en "Studies in History and Jurisprudence", Oxford, 1901.

OLLERO, A.: Derechos humanos y metodología jurídica, CEC, 1989.

OLLERO, A.: Derechos humanos. Entre la moral y el derecho, UNAM, México, 2007.

POLAINO-LORENTE, A.: Antropología e investigación en las ciencias humanas, Unión Editorial, Madrid, 2010.

RAWLS, J.: Liberalismo político, trad. S. R. Madero, FCE, México, 1996.

RODRÍGUEZ MOLINERO, M.: Derecho natural e historia en el pensamiento europeo contemporáneo, Editorial Revista de Derecho

Privado, Madrid, 1973.

RODRÍGUEZ PUERTO, M. J.: La Modernidad discutida: 'Jurisprudentia' frente a iusnaturalismo en el siglo XVI. Universidad de Cádiz, 1998.

SAUMELLS, R.: La ciencia y el ideal metódico, Rialp, Madrid, 1958.

SAUMELLS, R.: La geometría euclídea como teoría del conocimiento, Rialp, Madrid, 1970.

SAVIGNY, F. C.: System der heutigen römischen Rechts, Berlin, 1840.

SEIDENSTICKER, J. A. L.: Juristische Fragmente, Göttingen, 1802.

STAMMLER, R.: Rechts- und Staatstheorien der Neuzeit. Leitsätze zu Vorlesungen, Verlag von Veit and Co., Leipzig, 1917.

SUÁREZ, Fr.: Metaphysicorum Disputationum tomi duo, Coloniae, 1614.

TOMÁS DE AQUINO, In decem libros Ethicorum Aristotelis ad Nichomachum expositio, Marietti, Torino-Roma, 1964.

TOMÁS DE AQUINO, In IV Sententiarum (In Primum et Secundum Sententiarum), Tomus Sextus, "Opera Omnia”, Romae, 1570.

TOMÁS DE AQUINO, Liber de Veritate Catholicae Fidei contra errores infidelium seu "Summa contra Gentiles", Marietti, Torino-Roma, 1961.

Facultad de Derecho y Ciencias Sociales - Universidad de Valparaíso - Chile 
La fragmentación del discurso práctico, o el plano medio...

VIOLA, Fr.: De la naturaleza a los derechos. Los lugares de la Ética contemporánea, trad. V. Bellver, Comares, Granada, 1998.

WHEWELL, W.: The Philosophy of Inductive Sciences founded upon their History, $2^{\text {a }}$ ed. London, 1847.

Revista de Ciencias Sociales - Número 66 (2015) - Universidad de Valparáíso - ISSN 0716-7725-Valparaíso, Chile 